\title{
Data Processing Guide for the Environmental Sciences Division
}

\author{
R. H. Strand \\ R. J. Olson \\ K. D. Kumar \\ M. L. Tharp \\ J. A. Watts \\ N. A. Griffith \\ R. M. Anderson
}

\section{OAK RIDGE NATIONAL LABORATORY}

OPERATED BY UNION CARBIDE CORPORATION FOR THE ENERGY RESEARCH AND DEVELOPMENT ADMINISTRATION 


\section{DISCLAIMER}

This report was prepared as an account of work sponsored by an agency of the United States Government. Neither the United States Government nor any agency Thereof, nor any of their employees, makes any warranty, express or implied, or assumes any legal liability or responsibility for the accuracy, completeness, or usefulness of any information, apparatus, product, or process disclosed, or represents that its use would not infringe privately owned rights. Reference herein to any specific commercial product, process, or service by trade name, trademark, manufacturer, or otherwise does not necessarily constitute or imply its endorsement, recommendation, or favoring by the United States Government or any agency thereof. The views and opinions of authors expressed herein do not necessarily state or reflect those of the United States Government or any agency thereof. 


\section{DISCLAIMER}

Portions of this document may be illegible in electronic image products. Images are produced from the best available original document. 


\section{Printed in the United States of America. Available from National Technical Information Service}

U.S. Department of Commerce 5285 Port Royal Road, Springfield, Virginia 22161

Price: Printed Copy $\$ 4.50$; Microfiche $\$ 3.00$

This report was prepared as an account of work sponsored by the United States Government. Neither the United States nor the Energy Research and Development Administration/United States Nuclear Regulatory Commission, nor any of their employees, nor any of their contractors, subcontractors, or their employees, makes any warranty, express or implied, or assumes any legal liability or responsibility for the accuracy, completeness or usefulness of any information, apparatus, product or process disclosed, or represents that its use would not infringe privately owned rights. 
Contract No. W-7405-eng-26

DATA PROCESSING GUIDE FOR THE ENVIRONMENTAL

SCIENCES DIVISION

R. H. Strand, R. J. 01son, K. D. Kumar, M. L. Tharp ${ }^{1}$, J. A. Watts

N. A. Griffith, R. M. Anderson

ENVIRONMENTAL SCIENCES DIVISION

Publication No. 1075

\section{${ }^{1}$ Computer Sciences Division, Union Carbide Corporation Nuclear Division}

Date Published - August 1977

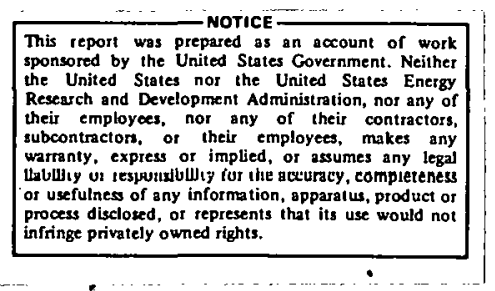

OAK RIDGE NATIONAL LABORATORY

Oak Ridge, Tennessee 37830

operated by

UNION CARBIDE CORPORATION

for the

ENERGY RESEARCH AND DEVELOPMENT ADMINISTRATION

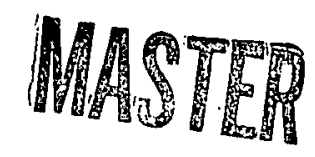




\section{THIS PAGE \\ WAS INTENTIONALLY \\ LEFT BLANK}


The authors express their appreciation to D. D. Huff and R. E. Moore of the Environmental Sciences Division for the ir constructive comments on the technical aspects of this report and to Anne Reinoehl for technical assistance in the preparation of the report. In addition to ERDA support, funds were provided in part by the Eastern Deciduous Forest Biome, US-IBP, funded by the National Science Foundation under Interagency Agreement AG-199, DEB76-00761, and in part by the Environmental Protection Agency under Interagency Agreement IAG-D5-E681. 
THIS PAGE

\section{WAS INTENTIONALLY LEFT BLANK}


STRAND, R. H., R. J. OLSON, K. D. KUMAR, M. L. THARP, J. A. WATTS, N. A. GRIFF-ITH, and R. M. ANDERSON. 1977. Data Processing Guide for the Environmental Sciences Division. ORNL/TM-5966. Oak Ridge National Laboratory, Oak Ridge, Tennessee. pp. 58

This data processing guide provides information on the availability and use of computer facilities for Environmental Sciences Division (ESD) personnel. This guide addresses recent data processing developments in ESD, little-known capabilities for handling data and using programs, and illustrates the mechanics of these developments and capabilities. Some of the specific developments are: (a) storing data or source code on tape or disk for insertion into a computer job stream, (b) creating a DECSYSTEM10 file from punched paper tape, (c) data storage and input using a computer terminal with cassette tapes, and (d) generation of microfiche output. 
THIS PAGE

\section{WAS INTENTIONALLY \\ LEFT BLANK}


ABSTRACT ................... . . . . . . . . .

LIST OF TABLES ................... . .

LIST OF FIGURES .......................... . . . . . . . .

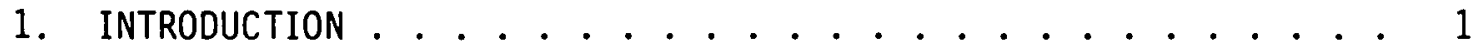

1.1 Getting Started .............. 2

1.1.1 Batch jobs on the IBM 360 computers ...... 2

1.1.2 Interactive processing on the DECSYSTEM10 . . . 3

1.1.3 Time sharing option (TSO) on the IBM 360/mode 175 computer ......... 3

1.1.4 Additional assistance ............ 3

1.2 Keypunching . . . . . . . . . . . . . 3

1.3 Data Processing Services . . . . . . . . . . 4

1.4 Statistical Consulting ........... 4

2. COMPUTER HARDWARE .................. 5

2.1 Computer Terminals . . . . . . . . . . . . . 5

2.2 Computer Telephone Ports . . . . . . . . . . . 6

3. REMOTE BATCH STATION (RBS) JOB PROCESSING . . . . . . 7

3.1 Stand-alone computing . . . . . . . . . . . 7

3.1.1 Memory/core . . . . . . . . . . . . . 7

3.1 .2 Background . . . . . . . . . . . . . . 9

3.1.3 Peripherals ................. . 9

3.1.4 Some special programs . . . . . . . . . . 11

3.1.5 MODCOMP job control language (JCL) . . . . . . 12

3.1 .6 FORTRAN . . . . . . . . . . . . . . . . 12

3.2 Remote Job Entry ............... 14

3.2.1 Routing DECSYSTEM10 Output to the RBS . . . . . 15

3.2 .2 Creating a Card-Image File on the IBM $360 \ldots 15$

3.2.3 Storing Data or Source Code on Magnetic Tape or Disk and Insertion of Data Set Into a Job Stream . . 16

3.2.4 Procedure for Creating an IBM 360 Data Set

from Paper Tape ........... . 18

3.2.5 Data Storage and Input Using a Computer Terminal with Cassette Tapes ... . . . . . . 20

3.2.6 Generation of Microfiche Output ......... 22

3.2.7 Card image output as a punched file from IBM 360 Computers to MODCOMP RBS ....... 28

3.2.8 Data processing examples using SAS . . . . . . 28

3.2.9 Procedure for creating data sets on the DECSYSTEM10 from IBM's Continuous System Modeling Program (CSMP) . . . . . . . . 35

3.2.10 Computer Graphics using DISSPLA . . . . . . 36

4. DATA PROCESSING SOFTWARE . . . . . . . . . . 42 


\section{THIS PAGE \\ WAS INTENTIONALLY \\ LEFT BLANK}




\section{LIST OF TABLES}

$\underline{\text { Table }}$

$\underline{\text { Page }}$

1.1-1 Individuals and Phone Numbers for Reference to Subject Areas in the Environmental Sciences Division . . . . . . 2

3.1-1 Sample MODCOMP JCL for executing a FORTRAN program on the MODCOMP . . . . . . . . . . . . . . . . 13

3.2-1 Sample computer program for generating data on microfiche using SAS and LCOM ............... 23

3.2-2 Commands for establishing an interactive TSO/SAS session

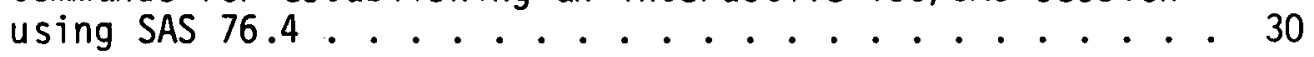

3.2-3 A sample execution of TSO/SAS interactive (underscored materials are user entered; each line of entered material is terminated with a carriage return) ......... 31

3.2-4 Logical sequence of program and control statements for executing a batch FORTRAN program with DISSPLA plotting . 38 
THIS PAGE

\section{WAS INTENTIONALLY LEFT BLANK}




\section{LIST OF FIGURES}

Figure

$\underline{\text { Page }}$

3.1-1 Environmental Sciences Division Remote Batch Station

Hardware ............... . 8 


\section{DATA PROCESSING GUIDE FOR THE ENVIRONMENTAL SCIENCES DIVISION}

\section{INTRODUCTION}

This guide provides information on the availability and use of computer facilities for Environmental Sciences Division (ESD) personnel. It is an updated and revised replacement to the first edition (ORNL/TM-4910, Strand et a1., 1975). The first edition presented many of the mechanical aspects of how to obtain access to the computing facilities. Recently, the Computer Sciences Division (CSD) has published the CSD Programmer's Notebook (available from R. Graham, 3-3502) which presents the "how to" information on accessing the computers. In order to minimize duplication of CSD's work, this report addresses data processing developments in the Environmental Sciences Division and illustrates the mechanics of these developments, citing the Programmer's Notebook where appropriate.

Data processing is becoming an increasingly important tool in environmental research; at the same time, computing techniques and computer equipment continue to change at a rapid rate. The current computer facilities available to ESD personnel are: (1) three main computers located in Building 4500 at X-10 -- the DECSYSTEM10, the IBM 360 mode 1 75 , and the IBM 360 mode 191 and (2) IBM 360 model 195 and IBM 370 model 155 computers at K-25. Each computer has its own peculiar characteristics and functions, requiring knowledge of the operating procedures for each. The DECSYSTEM10 provides interactive terminal capabilities, batch processing, and serves as a communications link to the IBM 360 models 75 and 91 computers. The IBM 360 models 75 and 91 primarily process batch computer jobs, with the 360 model 91 being a larger, faster machine. The 360 model 75 handles most of the magnetic tape jobs and certain IBM-compatible interactive computer terminal functions such as IBM's Time Sharing Option (TSO) and local textual interactive search programs (ORLOOK and RECON). (See Chapter 1 of Programmer's Notebook for more details on computing facilities.)

The Environmental Sciences Division has a Remote Batch Station (RBS) with 2 card readers, 2 line printers, 2 tape drives, disks, and other equipment to facilitate submitting and retrieving jobs to and from the ma in computers. This station has a MODCOMP II computer as a central processor. Stand-alone computing is available on this computer on a limited basis. In addition to the RBS, the Environmental Sciences Division has a number of teletype terminals in Buildings 2001, 2024, 3017 and 3504 to access the computers at $x-10$ and $K-25$. We intend that this guide will help orient and direct computer users to the available computer facilities and the ir required access procedures. We welcome suggestions for items to include in future updating to make the guide more useful to ESD personnel. 


\subsection{Getting Started}

The individuals cited in Table 1.1-1 provide a reference for questions on certain subject matters related to data processing. This section outlines steps required by new users to fulfill accounting requirements for the Computer Sciences Division prior to submitting jobs to the computers. Chapter 1 of the Programmer's Notebook gives additional information.

Table 1.1-1. Iridividuals and Phone Numbers for Reference to Subject Areas in the Environmental Sciences Division.

Computer Equipment Data Management Coordinator

ESD Computer Manuals Library Geographic Data Bases EDFB Information Center Programing Assistance Remote Batch Station Statistical Consulting
N. A. Griffith

R. H. Strand

R. M. Anderson

R. J. 01son

J. A. Watts

M. L. Tharp

N. A. Griffith

J. J. Beauchaimp
$3-6422 / 3-1110$

$3-6012$

$3-6012$

$3-6012$

$3-0396$

$3-0368$

$3-6422 / 3-1110$

$3-0368 / 3-7113$

\subsubsection{Batch jobs on the IBM 360 computers}

- Obtain a computer charge (request) number from the tape librarian, 3-1214. You will be asked for a project account number, a brief title for the general subject of the project, and the ESD division number (3380) in addition to your name, building, and phone number.

- Obtain user (name) initials from the computer center dispatcher, 3-0205. You will be asked for the charge number obtained above.

- Obtain manual from John Carpenter, 3-1703: CSD Programer's Notebook

- Computer manuals are available for reference in Room 226 of B7dg. 2001. (See Table 1.1-1 for contact person). 


\subsubsection{Interactive processing on the DECSYSTEM10}

- Utilize a terminal to print an application form by dialing one of the DECSYSTEM10 telephone numbers listed in section 2.2, attaching phone to acoustical coupler on the terminal; depressing carriage return, and entering HELP APPLY followed by a carriage return. Complete the resulting form according to the instructions and send it to the indicated address. A project programer number (e.g., 6200,21) and a password will be mailed which will allow you to access the DECSYSTEM10.

- Suggested manuals for the DECSYSTEM10 are currently available from John Carpenter, 3-1703:

DECSYSTEM10 Operating System Commands

DECSYSTEM10 TECO and F-10 Handbooks

- DECSYSTEM10 Hardware and Systems Software problems may be directed to Programming Assistance (3-0177) or Duane Wink ler (3-0177).

\subsubsection{Time sharing option (TSO) on the IBM 360/model 75 computer}

- Initiate a TSO account by calling 3-6221. You will need the charge number obtained above.

- Suggested IBM manuals available from Bob Graham, 3-3502:

Subject

TSO Command Language Reference

TSO Terminal User's Guide
Manual No.

GC28-6732

GC28-6763

\subsubsection{Additional assistance:}

A nearly complete set of computer manuals is maintained in room 226 of Building 2001 for reference by Division users. Personal copies of any of these manuals can be purchased from CSD by calling Bob Graham, 3-3502 (IBM materiai on ly), or John Carpenter, 3-1703 (non-IBM material). Computer Sciences Division has a programing assistance (PA) office (3-0177) located in Building 4500N which is open from 8:00 to 12:00 in the morning and from 1:00 to 4:00 in the afternoon (See Table 1.1-1 for Environmental Sciences Division PA).

\subsection{Keypunching}

Keypunch services are provided by CSD. Forms for coding material to be keypunched can be obtained from the Division computer manuals contact in Table 1.1-1 or they may be ordered from Stationery Stores in Building 7000 area. A "Request for Services" form (UCN-1010) for 
requesting the coded forms to be used as source material for keypunchers is available from the Computer Dispatcher (3-0205), or Stationery Stores; this completed form must accompany the material to be keypunched. These materials are then usually transferred to the Keypunch Services by placing them in the computer courier service "out" box located in your building. If a large volume of coded keypunch sheets are sent to Keypunch services, a copy of the keypunch sheets should be made for backup in case original sheets are lost before cards are obtained. The keypunched cards and original coding sheets will be returned to the user in the computer courier service "in" box.

For users wishing to do limited keypunching, keypunches are provided adjacent to Room 121, Building 2001, and in Room 18, Building 3017.

\subsection{Data Processing Services}

Many investigators have some background in computer programing, and we encourage them to do their own programming. However, for those with extensive data processing requirements, applications programing support is available from CSD on a contract basis. The amount of programming requested from CSD depends on the requirements of the project and the computer programming funds available within the project. This computer programing estimate should be made jointly by the investigator, project supervisor, and ESD Data Management Coordinator (Table 1.1-1). Once the data processing requirements have been defined and justified and the funding has been secured, then the appropriate person(s) can be contacted to perform the work. ESD project managers must then review the computer charges to the ir accounts to ensure that charges fall within budget constraints.

In addition to these arrangements, a programing assistant is available to ESD members for consultation (See Table 1.1-1). This person pro$v$ ides assistance on programing problems to ESD computer users and performs limited data processing services; that is, this person does not become involved in projects that would require extensive amounts of time over long periods. Please make an appointment for computer programming consultation.

\subsection{Statistical Consulting}

Statistical support is currently obtained from the Mathematics and Statistics Research Department in CSD. A statistician assigned to the Division from this Department is available on Tuesday from 9:00 to 3:00 and Thursday 9:00 to 12:00 (see Table 1.1-1). Individuals are encouraged to contact this person prior to performing an experiment or conducting a field survey to ensure adequate statistical design. Please make an appointment for statistical consulting in order to avoid scheduling conflicts. If a large amount of data will be generated in the 
project, consultation with the ESD Data Management Coordinator may eliminate the need to code and transcribe the initial observations to data sheets for computer processing and prevent unnecessary time delays.

\section{COMPUTER HARDWARE}

ESD currently has eight small digital computers in addition to the Remote Batch Station (RBS) facility. These minicomputers have been acquired for specific data acquisition and reduction functions. For users interested in the applications these computers are suited for, see the division computer hardware contact in Table 1.1-1. Capital equipment money can be obtained for computing hardware, and the Data Management Coordinator (Table 1.1-1) should be contacted by the program or project manager if the program or project has a need for computing hardware.

\subsection{Computer Terminals}

The Environmental Sciences Division has computer terminals for users " who desire to cormunicate with a computer via a telephone transmission line. These terminals are sumarized in the table below as to type, and maximum transmission speed (in characters per second). The exact location of each of these terminals varies according to the current user. Space limitations are such that no centralized area for terminals can be designated. (For contact person on exact locations and scheduling information see the computer equipment contact in Table 1.1-1).

\begin{tabular}{lc} 
Terminal Type & $\begin{array}{c}\text { Max. } \\
\text { Speed } \\
\text { (cps) }\end{array}$ \\
\hline TELETYPE & 10 \\
Texas Instruments (TI) & \\
Mode1 725 & 30 \\
TI Mode1 733 ASR & 30 \\
TI Model 735 & 30 \\
TI Model 745 & 30 \\
IO Device Mode 1 320 & 30 \\
TEKTRONIX MODEL 4014 (CRT) & 1200 \\
with Hard Copy & \\
Attachment (4610) & \\
TEKTRONIX MODEL 4012 (CRT) & 30
\end{tabular}

Print paper for these devices is stored in Room 104, Building 2001 for TELETYPES, Room 121, Bldg 2001 for TI devices, Room 119, Building 2001 
for TEKTRONIX hard copy device. IO devices use standard printer paper. Recycle paper from computer batch runs should be used for these terminals.

\subsection{Computer Telephone Ports}

Certain telephone numbers are available as computer ports into the IBM $360 /$ model 75 or DECSYSTEM10. The following is a tabulation of the telephone numbers, the computer and time sharing system they access, and the data transmission speed (in characters per second):

TELETYPE Compatible

Telephone

Number

$3-1011$

3-1051

3-1881

3-1071

3-1031

3-1061
System

TSO $360 / 75$

TSO $360 / 75$

DECSYSTEM 10

DECSYSTEM10

DECSYSTEM10

DECSYSTEM 10
Speed (cps)

10

30

$10 / 30$

$10 / 30$

$10 / 30$

$10 / 30$

IBM 2741 Compatible

Telephone

Number

3-1001

3-1021

3-1041
System

TSO $360 / 75$

TSO $360 / 75$

TSO $360 / 75$
Speed

15

15

15 


\section{REMOTE BATCH STATION (RBS) JOB PROCESSING}

The Remote Batch Station (RBS) consists of a Modular Computer System MODCOMP II/25 computer connected via telephone lines to the main computers (Fig. 3.1-1). The system is used to transmit jobs and data to the central computers and to receive output from the central computers. It has the capability to perform utility operations such as editing magnetic tapes and listing cards and limited capacity to execute computer programs written in FORTRAN. The system includes a 200 line-per-minute printer, a 1200 line-per-minute printer, a 200 card-per-minute and a 1000 card-per-minute card reader, disk facilities, a high-speed papertape reader and punch, a seven-track and a nine-track magnetic tape unit, 64K of core memory, and associated processors and controllers.

The RBS has significantly decreased the turn-around time (time between job submission and printing of results) for batch processing of ESD jobs by eliminating the transportation time required by the courier service. The MODCOMP performs data editing, listing, and processing independent of the main computers and will allow preprocessing of data with fast turnaround time and low cost.

The RBS has the capability to communicate directly with the IBM 360 computers via the CC70/8 which is a telecommunications link that performs functions similar to the DECSYSTEM10 in getting jobs into the IBM 360 queue.

\subsection{Stand-alone Computing}

The MODCOMP II is a minicomputer and can be used as a stand-alone computer. As a stand-alone computer it can be used for

(1) storing and editing of numeric and textual data. (See the insert feature in section 3.2.3),

(2) creating a user library containing programs written by users, and

(3) compilation and execution of user written FORTRAN programs.

Before the stand-alone features of the RBS can be used, it is necessary to understand the major features of the RBS organization.

\subsubsection{Memory/core}

The MODCOMP II has 64K of memory. The system programs are allocated $20 \mathrm{~K}$, with remaining $44 \mathrm{~K}$ available to users. If the communication link to the main computers is open, the foreground system for operating this link--the HASP work station--is allocated 10K. The remaining $34 \mathrm{~K}$ is available to the user for stand-alone computing. If the need arises, the HASP work station can be aborted and an additional 10K will be made 


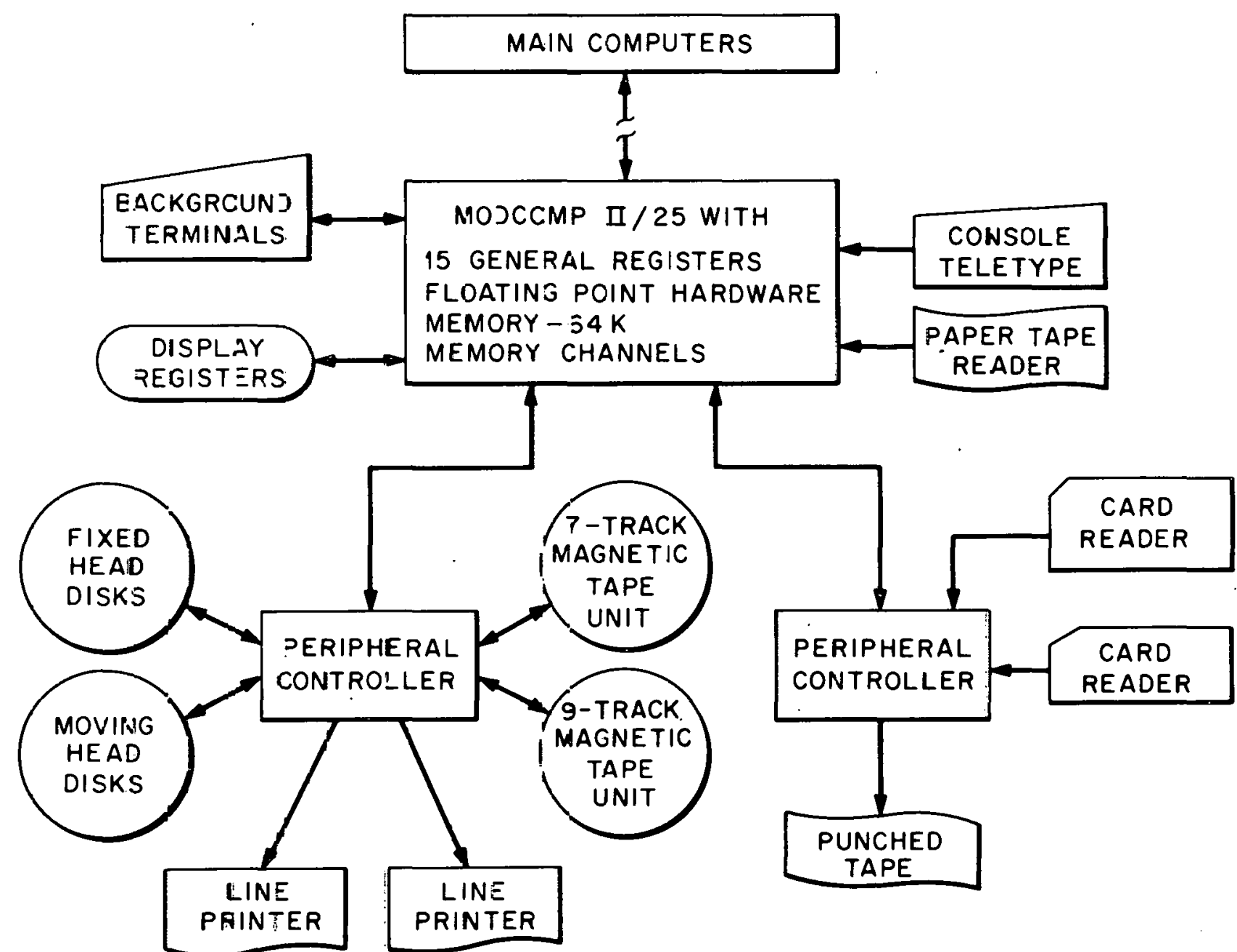

Fig. 3.1-1. Environmental Sciences Division remote batch station hardware. 
available to the user. This additional core is available only during non-prime time periods (between 5 P.M. and 6 A.M. weekdays and on weekends, by arrangement on $1 y$ ).

\subsubsection{Background}

The user addresses the machine through a background task. A task is a system program. There are two main b.ackgrounds namely (i) B background and $(i i)$ C background.

The $B$ background is always resident in core (unless the operator aborts it), while the $C$ background is activated when needed. Both the backgrounds have the same features. However, the B background is used primarily by the computer operator for management of the peripherals. The main operator console and the main card reader (fast card reader) are assigned to the $\mathrm{B}$ background. The slow card reader and the second console are assigned to the $C$ background. When both $B$ and $C$ background are active, the $34 \mathrm{~K}$ memory is portioned between the two in the desired manner (only the operator has the authority to change the core assignment).

The user can communicate with the backgrounds (either B or C - though in the following paragraphs we will assume that one is using the $C$ background) by means of the MODCOMP Job Control Language (JCL). When the user is communicating with the background, he is said to be in $C$ background monitor and by issuing the proper commands (see below under source editor for example) the control is transferred to either other system programs or to user supplied programs.

In principle, all the features of the machine are available to the user. However, certain peripherials (like moving head disk \#2) are protected and can be used only by the system operator. Sample MODCOMP JCL for assigning the 7 TRK tape drive is:

\$ASS $9=$ MT 1 .

This statement, entered from a terminal connected to the MODCOMP, assigns the logical unit number 9 to the 7 track tape drive. Similarly, \$ASS 9=MTO will assign the logical unit number 9 to the 9 track tape drive. Now the FORTRAN program can refer to the tape in the usual format:

For the assignment statements shown above, the logical record length is 80 characters.

\subsubsection{Peripherals}

The hardware of the RBS can be assigned by the user to his programs by using the proper MODCOMP JCL. 


\subsubsection{Tape drives}

There are 7 and 9 track (TRK) tape drives available to users. Data are usually stored in.compressed format (no trailing blanks on a record) on tapes. The MODCOMP will automatically uncompress the data records when they are read.

\subsubsection{Direct-access files}

There are 4 moving-head (MH) disks on the MODCOMP. They are numbered $0,1,2$, and 3 . MH2 (moving head 2) is used by the system and cannot be accessed by the user. MH1 and MH3 and approximately 80 tracks on MHO are available to users.

Each MH pack has 406 tracks, which have been partitioned into smaller segments of varying sizes. These segments can be addressed by their symbolic names. Contact the RBS operator for a complete list of symbolic names. The partitions of MH1 and MH3 are as follow:

No. of tracks

25
31
50
56
100
106
200
206
106

No. of segments

14
1
7
1
3
1
1
1
1

The MODCOMP JCL

\section{\$ASS $9=0 C 1$}

will assign the 2nd 100 track segment of MH3 to the program with a logical unit number of 9 . Observe that the larger segments overlap the smaller segments; hence, the user must be careful not to reassign the tracks that are already in use.

\subsubsection{Printers}

The printer can be used by all the programs. For example the MODCOMP JCi.

\$ASS $6=$ LO

will assign the printer the logical unit number 6 . 


\subsubsection{Card reader}

The slow card reader (200 cps) is assigned to the $C$ background. The JCL \$ASS $5=$ SI

will assign the card reader the logical unit number of 5 .

\subsubsection{Some special programs}

Under $B$ and $C$ backgrounds, two special programs of interest are source editor (SED) and library Update (LIB)

\subsubsection{SED}

As the name implies, SED is useful for editing of data. The SED is executed by entering the command:

\$EXE SED.

On the execution of this comand, control is transferred to the SED program. The SED commands (see Chapter 18 MODCOMP system Processors for details) do not start with the $\$$.

The SED can be used for

(1) listing of data from cards, tapes, and disk packs.

(2) creating tape and disk files,

(3) interactive data editing, and

(4) general data management.

An example of using SED for copying data from a 7-track tape to a -9-track tape is

$\$ \mathrm{JOB} \downarrow$

\$EXE SED $\downarrow$

ASS SI $=M T 1 \downarrow$

ASS SO $=$ MTO $\downarrow$

( $S I=$ source input)

COPY $\downarrow$

EXIT $\downarrow$

$\$ E O J \downarrow$

( $\mathrm{SO}=$ source output)

The SED can be used for changing records, deleting records, merging of two or more data sets, etc.

\subsubsection{LIBRARY UPDATE (LIB)}

The LIB is similar to SED except that LIB is used for the management of binary files. An example of a binary file is a compiled version of a 
FORTRAN subroutine. The LIB is used for deleting, adding, or merging such files. (For more details see Chapter 14 MODCOMP System

Processors.)

\subsubsection{MODCOMP Job Control Language (JCL)}

The MODCOMP Job Control Language is used to communicate with the machine. In the preceding paragraphs some examples of the MODCOMP JCL were shown. The MODCOMP JCL is much simpler than the IBM JCL, since the MODCOMP II is a much simpler machine. For details on MODCOMP JCL refer to Chapter 5 MODCOMP System Processors.

In Table 3.1-1 a sample MODCOMP JCL stream is shown. This JCL stream will compile, link edit and execute a user-supplled FORTRAN progralli. In the first step, the FORTRAN deck is read and comp led. In steep 2, the program is link edited with the MODCOMP FORTRAN library and a user library (DC1). In the last step, the program is executed. The program comunicates with the card reader $(5=C R C)$, printer $(6=L 0)$, the 7 track tape (7=MT1) and the disk partition DC2(8=DC2).

It is not necessary to write all the above MODCOMP JCL each time a program is run. Just as on the IBM, procedures can be set up on the MODCOMP and executed by 'invoking the proper name.

\subsubsection{FORTRAN}

MODCOMP II has a FORTRAN IV compiler. This compiler has most of the features of the IBM FORTRAN. A complete description of the MODCOMP FORTRAN is given in Chapter 9 of MODCOMP System Processors. Due to the limited core that is available for processing of the program, the user must become familiar with the concept of overlay. Uverlay is a mechanism for using the same core area for processing different subroutines. An overlayed subroutine is brought into core only when it is needed. There are several rules that must be adhered to in using the overlays. These are discussed in detail in Program Chaining and Over1ays, Chapter 12, MODCOMP System Processors.

The user must realize that $(a)$ the largest integer number that can be handled by the machine is $2^{15}-1$ (b) the accuracy of the machine is not as high as an IBM and (c) the MODCOMP is slower than the IBM. Sometimes it might be necessary to store 1 arge vectors on disks or tapes and bring them into core only when needed. This will increase the execution time.

The MODCOMP does not have a card punch at the present time. If the program outputs data that must be punched, the user can use the magnetic tapes or disks in lieu of cards. This file can then be relayed to Bldg. $4500 \mathrm{~N}$ for punching cards or kept as a MODCOMP file, listed and later used in a program. 
Table 3.1-1. Sample MODCOMP JCL for executing a FORTRAN program on the MODCOMP

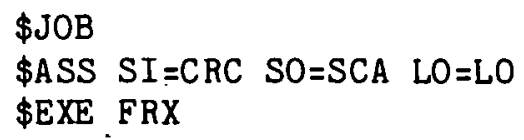

FORTRAN SOURCE DECK

ASSEMBLE STEP

$\$ \$$

\$WEOF SO

$\$ A S S \quad S I=S C A \quad B O=S C B \quad L O=N O \quad F M=F M$

$\$ E X E$ MAC

COMPILE STEP

\$WEOF BO

$\$ A S S \quad B I=S C B \quad B O=S C A \quad U L=D C 1$

\$EXE EDIT

LINK EDIT COMMANDS

LINK EDIT STEP

\$WEOF BO

$\$$ ASS $B I=S C A$

\$ASS $5=$ CRC $6=$ LO $\quad 7=$ MT $1 \quad 8=D C 2$

\$EXE MAIN, BI

DATA CARDS

GO STEP

$\$ \$$

\$EOJ 


\subsection{Remote Job Entry}

Computer card decks can be submitted to the main computers for batch processing either via the courier service to Building 4500 or through the Remote Batch Station (RBS) facility. Computer output can be either returned by the courier service or routed to the RBS for printing. This section describes the various capabilities of the RBS to enter card decks into the IBM 360 queue, to create files from cards, to list or duplicate card decks, or to print computer output files. The RBS is located in Room 121, Building 2001 (see Table 1.1-1 for contact person).

Users submitting computer jobs that require tapes or disks must supply the appropriate IBM Job Control Language (JCL) in a specific sequence. The required JCL cards are detailed in the CSD Programmer's Notebook, Chapters 2, 3 and 4 . A systeril of classifying jobs for scheduling them into the execution queue is also presented. It is important to adhere to the rules for coding of JCL and the order of the JCL cards as described in the Programmers Guide. Even a single space or mispunched character, especially in the JOB card, can mean complete failure of a job with no subsequent printout.

Since the RBS does not have a card punch, any jobs that generate punched card output must include a route card so that the punched cards will be produced at the main facility, Building 4500N. An example of the job card and route cards that would produce output on the RBS printer and punch cards at Building 4500N from any job that is not submitted through the RBS is given below: (Note the number zero has a slash through it when used in computer examples throughout this manual-lhe letter 0 does not.)

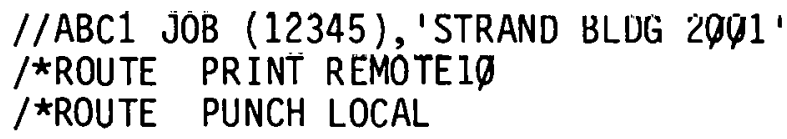

Those jobs submitted through the RBS do not require the "ROUTE PRINT" card to have printed output occur on the RBS printers. The RBS has two line printers -- an upper case only and an upper or lower case printer. To print upper/lower case on the RBS the user must supply the following cards:

//ABC1 JOB (12345), 'STRAND BLDG 2øø1'

$/ \star$ ROUTE PRINT REMOTE1Ø

$/ \star * O P T I O N S$ FORM $=1 \emptyset \emptyset 1$

The JOB card must be replaced with one unique to the user. If the OPTIONS card is left off, the printed output will be upper case only. 


\subsubsection{Routing DECSYSTEM10 output to the RBS}

Files existing on the DECSYSTEM10 may be printed on the RBS printer by coding the following information while logged onto the DECSYSTEM10 via a terminal ( $\downarrow$ represents a carriage return on the terminal and characters that are underlined are those generated by the system to prompt the user):

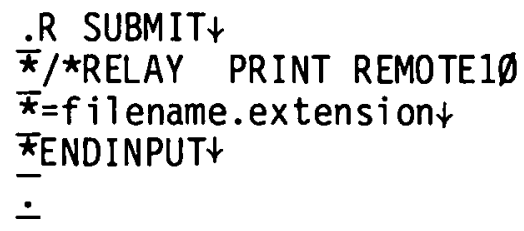

name bldg \# $\downarrow$

The "filename.extension" is to be replaced by the user's filename and file extension (see DECSYSTEM10 Programmer's Notebook, Chapter 17 for help on proper extensions). The character "/" is coded in column 1; the word "PRINT" begins in column 10; and the word "REMOTE10" begins in column 16. The person's name and destination of output begin in column 42.

More complete routing and relaying information is described in Chapter 4 of the Programmer's Notebook. This chapter al so describes the options for obtaining single or multiple listings or copies of card decks with instructions for special print forms. Other useful procedures in this chapter are saving IBM 360 output on your DECSYSTEM10 files, creating a DECSYSTEM10 file using the /*RELAY command, and how to access these files.

\subsubsection{Creating a card-image file on the IBM 360}

\subsubsection{Semi-permanent direct access files}

Persons wishing to create a file on the IBM 360 disk space may do so by submitting a job containing IBM $360 \mathrm{JCL}$ cards coded according to the description given in the sample program below (see Chapter 4 Programer's Notebook for description of disk files):

//ABC1 JOB (12345), 'STRAND 2øø1'

$/ /{ }^{*}$ CLASS CPU91 1 1øS, REG ION $=27 \emptyset \mathrm{K}$

$/ /$ EXEC PGM=IEBGENER

//SYSPRINT DD SYSOUT $=A$

//SYSIN DD DUMMY

//SYSUT2 DO UNI T=SPDA, DISP=(NEW,CATLG), DSN=T.ABC02345. name,

// SPACE $=$ TRK $,(5 \emptyset, 5), \mathrm{RLSE}), \mathrm{DCB}=(\mathrm{RECFM}=\mathrm{FB}, \mathrm{BLKSIZE}=728 \emptyset, \mathrm{LRECL}=8 \emptyset)$

//SYSUTI DD *

[data deck]

/*

/I 
The information on the JOB card must refer to the user's job number and charge number (see Section 1.1), destination of the printed output and user's name. The information following the DSN and SPACE parameters are determined from the description in Chapter 4 of the Programmer's Notebook. The duration the data set remains on the disk depends primarily on the space required. Details on time and space requirements are also in the Programer's Notebook.

\subsubsection{Permanent direct access files}

Division personnel wishing to create files on disk for access by programs executed on the BIdg. $4500 \mathrm{~N}$ IBM 360 computers can do so by following the instruction below. This disk space is to be used for files which require frequent access by one or several users. However, space on the disk device described below is limited and as the disk becomes filled, it will become increasingly important to use this space efficiently. The IBM JCL and program are coded as follows:

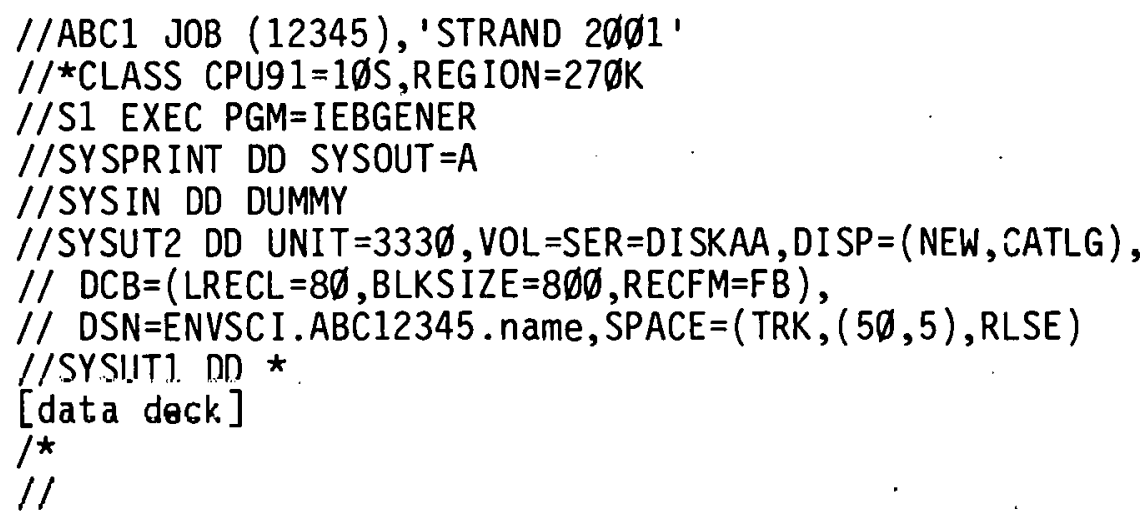

In this example, the letters $A B C$ in the DSN parameter must correspond to the user's job name initials on the job card. These letters are unique to each user. The numbers 12345 must correspond to a user's computer charge number. The "name" must be 1-8 characters long and be unique to a user's file. The "SPACE=" parameter, designated by the user, indicates the space required for storing the data. See ESD Programing Assistance (Table 1.1-1) for help in increasing this quantity.

\subsubsection{Storing data or source code on magnetic tape or disk and insertion of data set into a job stream}

\subsubsection{Storing data or source code on tape or disk}

Remote Batch Station users now have the option to store 80-column card images on magnetic tape or disk using the MODCOMP. The tape or disk files created differ from IBM or DECSYSTEM10 files but can be inserted 
into the stream of a computer job being submitted through the RBS card reader. This eliminates reading in large program or data card decks repeatedly. It also allows a user to convert a CSD defined "set-up" job (a job requiring a magnetic tape at the main computer) to a "non-setup" job by reading the data to be used by a program from a tape or disk at the RBS. The magnetic tape or disk file is written in unblocked 80-column card images using ASCII format and can be either source or data decks. Although hex decks cannot be accommodated by the MODCOMP, this option may be added if there is sufficient interest.

Magnetic tape or disk files can be created by bringing the cards to the RBS and requesting the service. At the present time, limited storage space requires that users store their private tapes in the ir own offices.

\subsubsection{Insertion of a data set into a job stream}

Accessing a tape or disk file is accomplished by inserting a special card in the deck making up an IBM 360 job stream at the position where the file is to be read. For example:

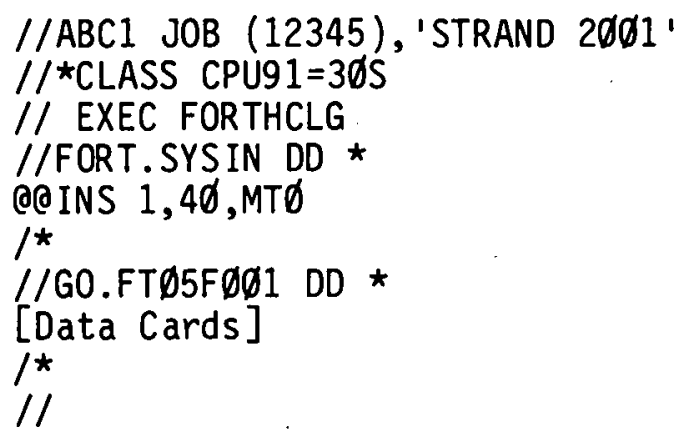

Another example executing SAS76 and reading a tape (ddname = DATA) created on the MODCOMP follows:

//ABC1 JOB (12345), 'STRAND 2øØ1'

$/ / \star$ CLASS CPU91 $=10 S$

//S1 EXEC SAS76

//SAS.DATA DD *

QDINS $1,4 \varnothing$, MTO

$1 *$

//SAS.SYSIN DD *

DATA FROG; INFILE DATA; INPUT ...;

[other SAS statements]

$1 *$ 
In the above examples, the statement $\oslash \oslash$ INS $1,4 \emptyset, M T \emptyset$ instructs the MODCOMP system to insert at that point a file located on magnetic tape transport $\emptyset$. When the first end-of-file mark is read by the magnetic tape unit, the processing of card input resumes. To submit a job using a MODCOMP tape, simply leave the card deck together with the tape in the Input Box for the RBS. Currently, if more than one file exists on the tape, the operator must be instructed by the user as to what file to position the tape prior to submitting the job.

\subsubsection{Procedure for creating an IBM 360 data set from paper tape}

Occasionally users may have a need for processing paper tape into a more manageable form, such as magnetic disk or magnetic tape. We will describe how to process a data set on paper tape and handle it through the main computers.

\subsubsection{Create a file on DECSYSTEM10 from paper tape}

Complete a REQUEST FOR SERVICES card (UCN-1010) and send the paper tape with card to the computer dispatcher in Bldg. 4500N by the courier service. An example of the completed REQUEST FOR SERVICES card is shown below. In this example, a file named AU $3 \varnothing \emptyset \emptyset$ is created in the project programmer area $[62 \emptyset \emptyset, 52]$. Each user must make changes to the user name, request number, and project-programmer number to correspond to

REOUEST FOR SERVICES

\begin{tabular}{|c|c|c|c|c|}
\hline \multirow[t]{9}{*}{ IN } & \multicolumn{2}{|c|}{$\begin{array}{l}\text { NAMRE C. C. COUTANT } \\
\text { BUILDING NUMBER } \\
200] \\
\end{array}$} & \begin{tabular}{|l} 
REQUEST NHMABEQ \\
4359 \\
ROOM NUMBER
\end{tabular} & \multirow[t]{9}{*}{ OUT } \\
\hline & WOKK TU BE DÖNE & DONE BY & COMMENTS & \\
\hline & $\square$ KEYPUNCH & & \multirow{7}{*}{$\begin{array}{l}\text { Please use PIP } \\
\text { to read paper } \\
\text { tape into } \\
62 \emptyset \emptyset, 52 \\
\text { using fi lename } \\
\text { AU3 } \$ \emptyset \emptyset \text {. } \\
\text { Please return } \\
\text { paper tape. }\end{array}$} & \\
\hline & $\square$ REPRODUCE & & & \\
\hline & $\square$ SORT & & & \\
\hline & $\square \quad$ LIST & & & \\
\hline & $\square$ INTERPRET & & & \\
\hline & X] OTHER & DECSYSTEMI & & \\
\hline & DEADLINE (IF URGENT) & & & \\
\hline
\end{tabular}

those assigned to the user. The filename must be unique to each file created within a project-programer area. 


\subsubsection{Obtain a listing of DECSYSTEM10 file created from paper tape}

Obtaining a listing of the file after determining that the tape has been read in can be done by either waiting for the paper tape to be returned or logging onto the DECSYSTEM10 and checking the directory to see if the file exists in your disk area, e.g.,

$\stackrel{-D I R}{ }$ AU3090

A line printer listing can be obtained from the DECSYSTEM1O line printer by using the command:

\section{.0 AU3 $60 \varnothing \downarrow$}

The listing can be routed to the remote batch station via the IBM 360 system using the following commands (Note: $\downarrow$ indicates carriage return):

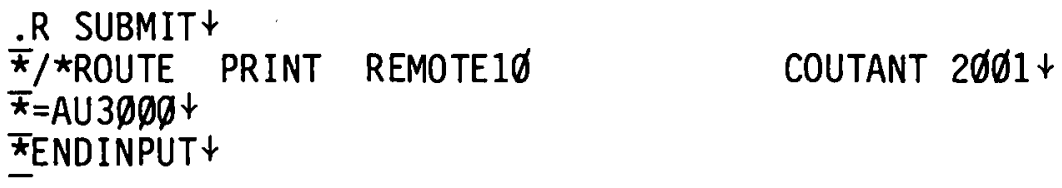

\subsubsection{Edit the DECSYSTEM10 file created from paper tape}

Edit the file to correct errors using either TECO or a special editing program such as LINDEL, a line deletion program for unacceptable values in a given data set. These procedures are documented in the DECSYSTEM10 manuals. Cal1 J. Carpenter, 3-1703 for a copy.

\subsubsection{Create a temporary file on the IBM 360 system using the edited} DECSYSTEM10 file

Create a temporary file on the IBM 360 system using the edited file created in $A$ as input. The example below shows a file created on the DECSYSTEM10 containing the IBM JCL needed to create an IBM 360 file. This DECSYSTEM10 file can be edited and the line following "//SYSIN DD *" modified for each new file created from the paper tape. Items italicized are those which must be changed to correspond to each new filename.

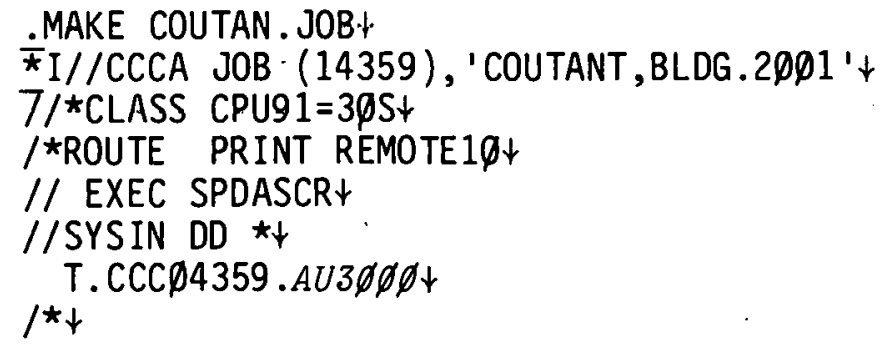


// EXEC PGM=IEBGENER $\downarrow$.

//SYSPRINT DD SYSOUT $=A \downarrow$

//SYSIN DD DUMMY

//SYSUT2 DD DSN=T. CCC $4359 . A U 3 \varnothing \varnothing \emptyset, U N I T=S P D A, \downarrow$

// DISP $=($ NEW, CATLG $)$, SPACE $=($ TRK $,(10 \varnothing, 5), R L S E), \downarrow$

$/ / \mathrm{DCB}=\mathrm{BLKSIZE}=2 \varnothing 48 \downarrow$

//SYSUT1 DD $\star \downarrow$

$=A U 3 \varnothing \varnothing \emptyset \downarrow$

$1 * \downarrow$

$\$ \$$

$\star E X \$ \$$

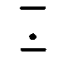

\subsubsection{Submit the DECSYSTEM10 file to the IBM 360}

To submit the job file created above to the IBM 360 , type

.IBM COUTAN.JOB

\subsubsection{Analyze the IBM 360 file using SAS}

We have presented a sample program used for analys is in the Thermal

Effects Program in the Division. This series of instructions was also placed into a file on the DECSYSTEM10 for submission, as above, to the IBM 360s. It is important to note the filenames (italicized items) which refer to the files created above.

[a valid job card goes here]

$1 / *$ CLASS CPU9 $1=1 M$

// EXEC SAS76

//SAS. AU3 $\varnothing \varnothing \emptyset$ DD DSN=T.CCC 94359 . AU3 $\varnothing \varnothing \varnothing, D I S P=S H R$

//SAS. SYSIN DD *

[SAS STATEMENTS]

TITLE ' THERMAL PREFERENCE OF THE STRIPED BASS TAG 12228 AUG 75';

DATA TESTSAS; INF ILE AU3 900 ;

INPUT HOUR 1-2 MINUTE 3-4 SECOND 5-6 MSEC 8-11;

Program statements and procedure statements are placed here for

$$
\text { /* }
$$

$/ 1$

\subsubsection{Data storage and input using a computer terminal with} cassette tapes

The Division has a remote computer terminal with cassette tape handling capabilities. This terminal is a Texas Instrument Model 733 ASR with 
dual cassette tape handlers. We have used this terminal directly connected to the MODCOMP computer as a background terminal for submitting commands, editing files, and receiving output from programs. The cassette tapes allow the user to spool output onto cassettes rather than printing an entire sequence of data values. Following rewind, the data can be selectively played back onto the terminal.

This terminal also can be used as a dial-up terminal, accessing remote computers by telephone connections and by an acoustic coupler attached to the terminal. We will not discuss all the possibilities for dial-up access. Rather we show the procedure for recording onto the magnetic cassette tape of this terminal while logged into the DECSYSTEM10. Then we show how to take the output created on the cassette while logged into the DECSYSTEM10 and reinsert these data into the DECSYSTEM10 creating an online file again. (These procedures were determined through the assistance of C. E. Hammons, formerly of the Computer Sciences Division.)

\subsubsection{To copy a file from DECSYSTEM10 to cassette TAPE}

LOGIN ppn't .password is entered here. The system will print messages describing new developments and changes in the DECSYSTEM10.

. TTY PAGE $\downarrow$

.TTY NO FILL

<CNTRL>S

- place all switches in line mode

- Set the cassette to be recorded to record mode

- Push the rewind button to rewind the cassette

- Push the load button

.TYPE filenamet

- Push the record on button

.$<$ CNTRL $>Q$

- Following the completion of data recording, push the record off button

- Place all switches in local mode

- Push the record on button

.$<$ CNTRL $>Z$

.$<$ CNTRL $>C$

.$<$ CNTRL $>S$

$.<C N T R L>D$

-Push the record off button 


\subsubsection{To play back cassette tape into DECSYSTEM10 file}

.LOGIN ppn $\downarrow$

-TTY TAPE $\downarrow$

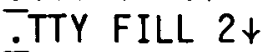

- Place all switches in line mode

- Set cassette to playback mode

- Rewind the cassette tape

- Push the load button

.R PIPt

$\bar{\star}_{\mathrm{f}} \mathrm{i}$ l ename $=\mathrm{TTY}: \downarrow$

$\overline{<}$ CNTRL $>$ Q

- Push the continuous playback button

- Following the last record being transmitted from the tape, type the following control characters:

$<C N T R L>Z$

$\star<C N T R L>C$

$<C N T R L>S$

$<C N T R L>D$

$\dot{-}$

A cassette tape recording device for gathering data in the field on cassette tape is available. The data on tape can then be read into the computer for analysis. The cassette tapes are considerably easier to use and have fewer errors than do paper tape. See computer equipment contact (Table 1.1-1) for information on this device.

\subsubsection{Generation of microffche output}

Occasionally investigators will have a need to reduce the volume of paper for a publication or of output generated by a computer program. When appendices are used in publications to provide supplementary information for a publication, e.g., computer program listings or lengthy data files, the volume of materials can be reduced by placement of the information on microfiche. Cost savings for microfiche versus paper output are dependent on the volume of material to be reproduced. Approximately 240 pages of computer printout will fit on a $5 \times 7$ microfiche at $48 x$ reduction. Cost evaluation will not be discussed in this note, but the technical aspects of using the Statistical Analys is System (SAS) (Barr, A.J., J. H. Goodnight, J. P. Sall, and J. T. Helwig. 1976. A User's Guide to SAS76. SAS Institut.e, Raleigh, N.C. 329 pp.) for preparing computer output for reproduction on microfiche will be discussed. It is assumed that the user is familiar with the basic input and output instructions in SAS. Hence, there will be no discussion of the SAS statements other than those used to generate the microfiche. For new staff unfamiliar with SAS, we suggest contacting Division programming assistance (Table 1.1-1) for counseling and advice on generating microfiche with SAS. There are four categories of code within the listing presented in Table 3.2-1 which may be used to 
Table 3.2-1. Sample computer program for generating data on microfiche using SAS and LCOM

$1 /$ RASCOAL JOB $(14840) \cdot)^{\circ}$ STRAND 2001 '

$/ / *$ CLASS CPU9 1=2 K, L INES $=2$, REGION $=270 \mathrm{~K}, \mathrm{SPECIAL}=\mathrm{TAPE}$

// EXEC SAS76

$/ /$ SAS. REP DD UNIT $=3330, \mathrm{DISP}=($ OLD, KEEP), DSN $=$ ENVSCI . RAS 14840, CUSHREP,

$1 /$ VOL $=S E R=D I S R A A$

//SAS. FTO4P001 DD ONIT $=S Y S D A, D I S P=(N E H, P A S S), D S N=86 T$,

$1 / D C B=(R E C F H=F B A, L R E C L=133, B L K S I Z E=1064), S$ PACE $=(C Y L,(30,10), R L S E)$

/ SSYSIN DD *

DATA CONTEN:

INFILE CARDS:

INPUT CONTENTS $\$ 1-80$;

CARDS:

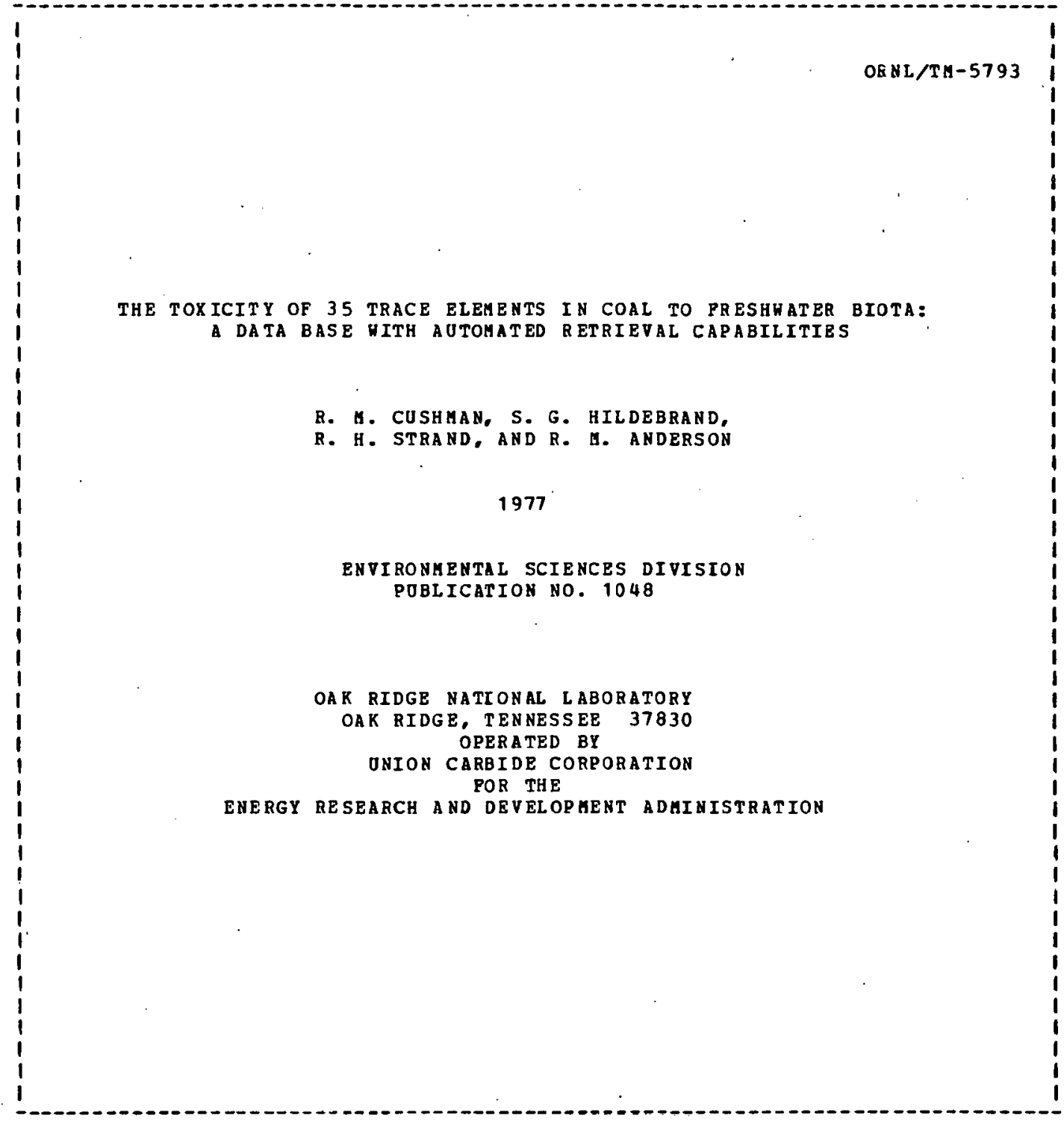


Table 3.2-1. (continued)

THE POLLORING IS A DESCBIPTION OF THE COAL CONVERSION TOXICITY DATA BASE. THE VARIABL BS INCLUDED HITHIN THE DATA TABLES AND THEIR DEPINITION ARE INCLODED BELON. THE PIRST SET OP VARIABLE DEPINITIONS IS OSED IN THE DATA TABLES. THE SECOND SET OP VARIABLE DEPINITIONS IS OSED IN THE PERCENT FREQUENCY TABLES.

$-$ VARIABI.ES OSED IN DATA TABLES

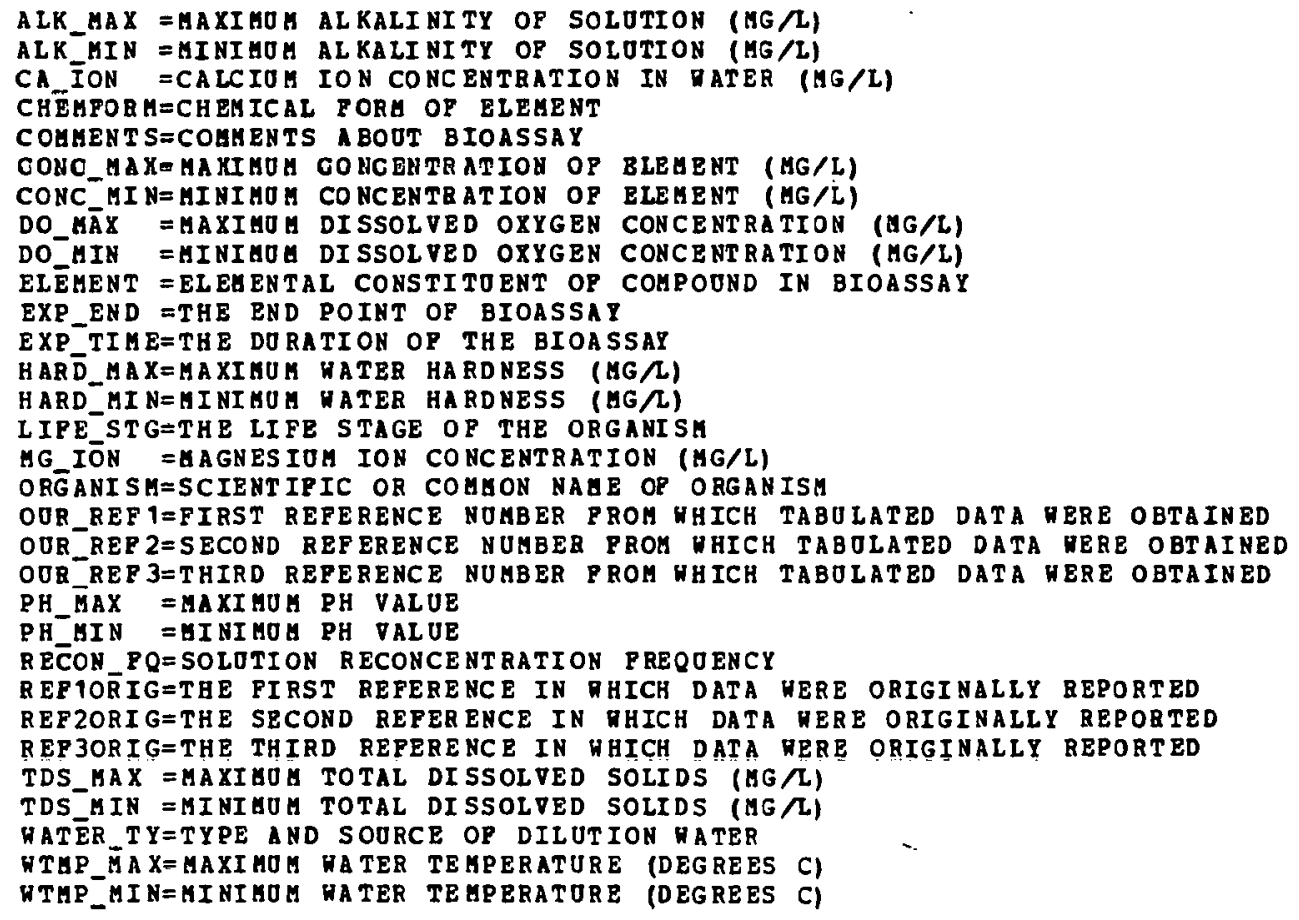


Table 3.2-1. (continued)

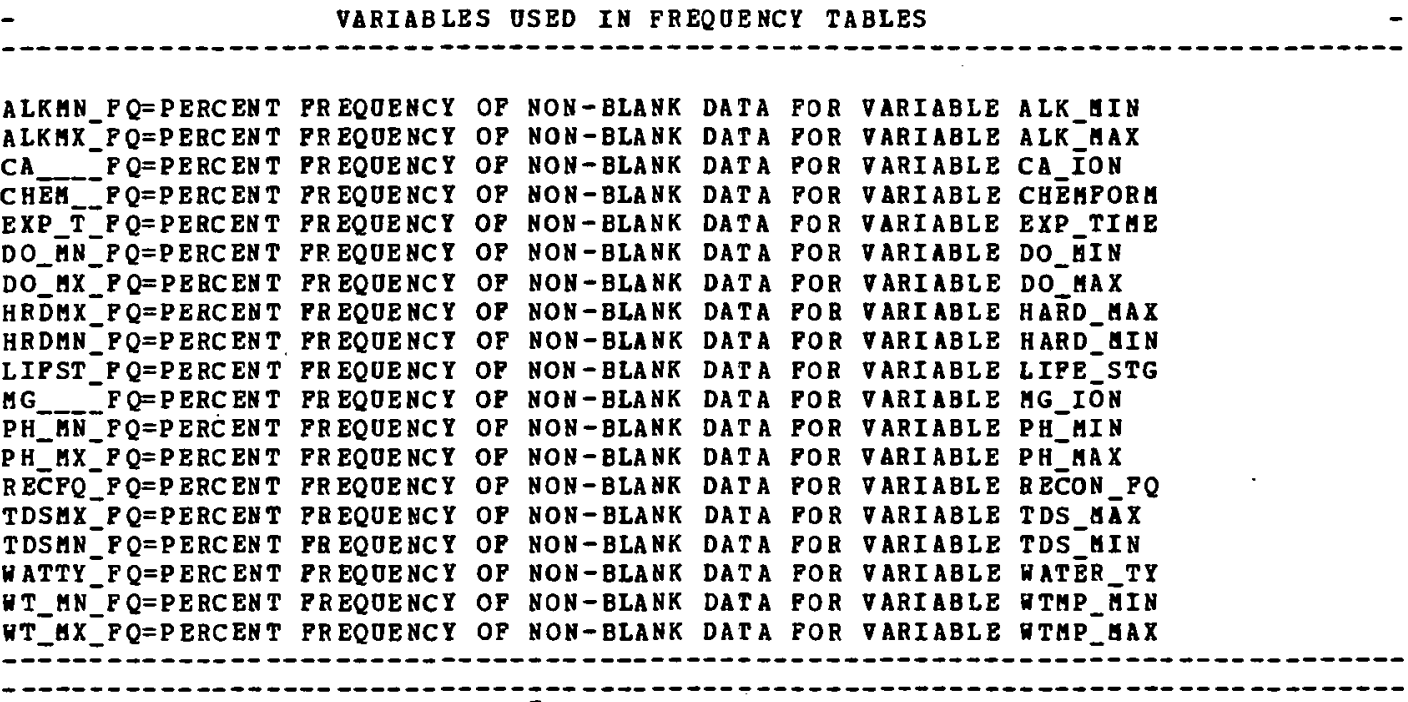

TO GIVE THE USER A CONDENSED SOMHARY OF TAE AKOONT OF DATA HHICH IS PRESENT POR EACH VARIA BL E HTHIN THE DATA BASE, WE HAVE SOKUABIZED THIS INFORMATION AS PERCENT FREQUENCY OP NON-BLANK DATA POR EACA VARIABLE VITHIN EACH

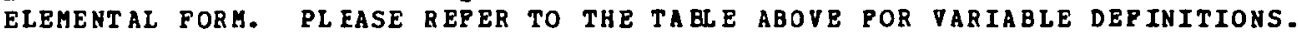

DATA FREQ: INFILE CARDS END=END SQ;

INPOT ELEM CBD 11-13 SEQ 14 ELEG \$26-27 CONC MAX 38-45 4 CONC MIN $28-364$

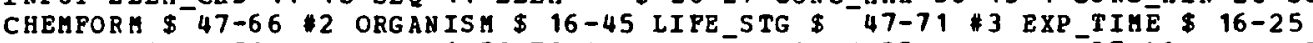
EXP_END \$27-56 RATER_TY \$58-78 4 RECON_PQ $\$ 16-35$ HTMP_HAX 37-40 WTMP_HIN $42-\overline{4} 5$

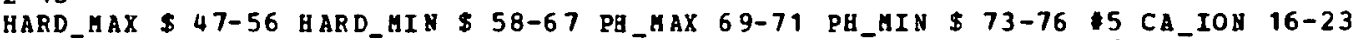
HG_ION 25-32 DO MAX 35-39 DO_HIN 41-45 TDS MAX 47-52 TDS_MIN 54-59

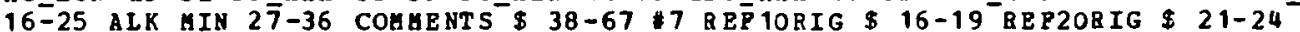
REP3ORIG \$ 26-29 OOR_REP1\$31-34 OUR_REP2\$36-39 OOR_REP3\$41-44;

$\star$ :

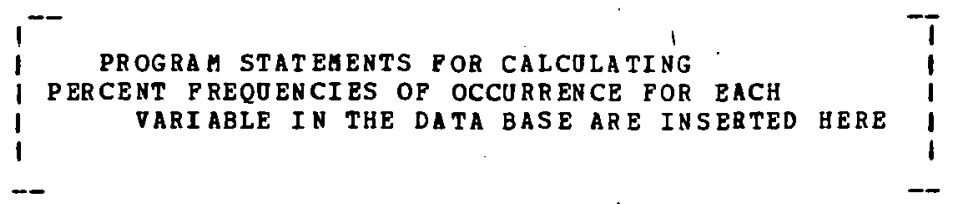

CARDS:

DINS 1,40, HT 
Table 3.2-1. (continued)

DATA TABCON; INFILE CARDS; INPUT CONTENTS \$1-80; CARDS:

THE TABLES HHCH FOLLOR ARE FORAATTED SO AS TO CONTAIN THE IAFORAATION FOR EACH EXPERIGENT ON A SINGLE PAGE. PAGE NUHBERS ARE IN OPPER RIGHT HAMD CORNER. OF EACH PAGE. A SINGLE OBSERVATION CONSTITOTES THE INPORMATIOA PROM ONE EXPERMENT. BECAUSE THE LENGTH OP A SI NGLE IINE NAS TOO GREAT TO PIT ACROSS A PAGE. THE LINE IS CONTINOED BEG INNING APPROXIMATELY HALP RAY DORH THE SAHE PAGE. THOS THE CONTINOATION OF OBSERVATION ONE (LINE ONE) BEGINS HALPRAY DORH THE PAGE WITH THE VARIABLE HATER_tY. HHERE ONLY A SINGLE VALOE OCCURS EITHER AS A HAXIHUH OR A UINIMUA, A RANGE OF VALOES HAS NOT USED $P$ OR THAT VARIABLE IN THE BIOASSAY TEST CONDITIONS.

DATA REBRCTS;

INPILE CARDS END=END SH:

INPOT ELEH_CRD 11-13 SEQ 14 ELEHENT $\$ 26-27$ CONC_MAX 38-45 4 CONC_MIN 28-36 4 CHEMFORA \$47-66 \#2 ORGANISA \$16-45 LIPE_STG\$ 47-71 \#3 EXP_TIME $\$ 16-25$ EXP_END \$ 27-56 NATER_TY \$58-78 14 RECON_PQ \$ 16-35 MTAP_MAX 37-40 NTHP_MIN \$ 42-45

HARD_MAX \$ 47-56 HARD_AIN. \$ 58-67 PH_MAX 69-71 PH_HIN \$ 73-76 5 CA_ION 16-23 MG ION 25-32 DO WAX 35-39. DO.MIN 41-45 TDS MAX 47-5̌ TDS MI 54-59 $\overline{6}$ ALK MAX

16-25 ALK_MIN $2 \overline{7}-36$ COMAENTS $\$ 38-67$ \# BEP 10RIG \$16-19-RER2ORIG\$21-24 REP3ORIG $\$ 26-29$ OUR_REP1 \$ $31-34$ OUR_REP2 \$36-39 OUR_REP3 \$ 41-44; DROP SEQ: CARDS ;

DOINS $1,40, \mathrm{MT} 1$

PROC SORT; BY ELEHENT CONC_MIN:

DATA EPFECT 1; SET ERFECTS; OBS + 1; KEEP OBS ELEHENT CHEAPORM ORGANISH;

PROC SORT DATA=EPPECT 1; BY ORGANISH:

PROC PRINTTO ONIT=4 NEW:

PROC PRINT DATA =CONTEN N;

ID CONTENTS:

TITLE CONTENTS DESCRIPTION OF COAL CONVERSION TOXIC BPPECTS DATA BASE;

TITLE2 (N= POLLOHING THE LAST LINE REFERS TO NUABER OP LINES IN PILE);

PROC PRINT Y DATA=FREQ; ID ELEH:

PORMAT

CHEM_PQ LIFST_FQ EXP_T_PQ HATTY_FQ RRCPQ_PQ NT_HX_PQ HT_MN_PQ

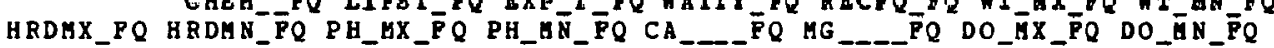

TDSMX_PQ TDSMN_FQ ALKUX_FQ ALKMH_PQ

5 : :

TITLE PERCENT FREOU ENCY OF DATA VALOES POR CERTAIN VARIABLES IN THE DATA BASE: TITLE2 THOSE VARIABLES NITB A FREQOENCY OF OCCORRENCE OP 100\% ARE NOT INCLODED; TITLE3 (N= NOHBER OF ELEHENTS IN DATA BASE HAVING VARIOOS CHEHICAL PORHS): TITLE4 (N=NOHBER, POLLORING THE LAST LINE, REPERS TO NOABER OP LINES IA TABLE); PROC PRINT DATA=TABCON N: ID CONTENTS;

TITLE CONTEHTS DESCRIPTION OF COAL CONVERSION TOXIC EFPECTS DATA BASE:

PROC PRINT DATA $=$ EPF ECTS:

TITLE TOXIC EPPECTS FROH COAL CONVERSION EPPLUENTS DATA BASE;

PROC PRINT DATA = EPPECT1 : ID OBS:

TITLE TABLE OF ORGA NISHS (SORTED). ELEMENT, CHEMICAL PORM OP THE ELEHEHT, AND : TITLE2 A CROSS REFERENCE TO THE ENTIRE RECORD (OBS) IN PRECEDING DATA TABLES; DATA NOLL_; INPILE REF; INPOT; PILE PRINT NOPRINT; POT INPILE_:

TITLE BIBLIOGRAPHY OF CITED REPERENCES IN TOXIC EPPECTS DATÁ BASE;

PROC PRINTTO;

$/ / C O M$ EXEC PG $H=L C O H$, REG ION $=64 \mathrm{~K}$

/STEPL IB DD DSN=COHO4. LC OH, DISP $=S H R$

$/ / I N$ DD DSH $=8$ ST, ONI T $=S Y S D A, D I S P=$ (OLD, DELETE)

/ $/$ DUMAY DD SYSOUT=A

$/ / Q 105 T$ AP DD ONIT=T APE9, DISP= (NER, KEEP), DSNAME=COMTAPE,

// LABEL= (,SL, ,OOT).

I/ VOL $=S E R=X 18597$

$(/ Q 105 P R T$ DD SYSOUT $=A, D C B=(R E C F M=P B A, L R E C L=133, B L K S I Z E=1064)$

//SYSTN DD *

ENCL TO ORNL/TH-5793, CUSHAA, R. H. ET AL.TOXICITY OF 35 TRACE ELEHENTS IA COAL̈ $1 /$ 
generate a microfiche. These categories are: (a) IBM Job Control Language--primarily those lines in Table 3.2-1 beginning with '//', SAS statements--those lines in Table 3.2-1 ending with a ' ' ', (c) data--80-column card input from cards, tape or disk, and (d) a program to generate the microfiche file from a file comprised of data arranged in the desired order for microfiche generation. Once the code has been executed and a microfiche file generated on magnetic tape, the final step is to request that a microfiche be generated. A request-forservices form (UCN-7342) is used to complete the instructions, e.g., number of copies, tape number, charge number, etc., to the computer operator for generating the microfiche.

The major effort required for microfiche generation is file preparation --particularly when a specific format is desired. SAS is very helpful in this effort, since it allows descriptive textual material and it will prepare data tables with titles and variable names as the column headings. In Table 3.2-1, six different data files are created and prepared for output to a disk file--\&\&T. The disk file is used in the generation of the microfiche tape file.

The first of the six data files is called CONTEN and contains textual material entered into 80-column card images. It is important to note that the text for this file will appear in the microfiche exactly as it appears on the cards. The data for file CONTEN ends with the creation of another data file--FREQ. This data file contains percent frequencies of occurrence of data for each variable defined in the input data. The frequencies are calculated using SAS program statements. The final form of the data file will be a single page of percentage frequencies showing the amount of non-missing data for each variable over all observations.

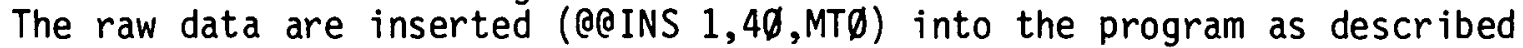
in section 3.2.3.

The third data file (TABCON) contains textual data that will precede the tabular sumary of the raw data contained in the fourth data file EFFECTS. The fifth data file -EFFECT1-is a subset of the EFFECTS data file and contains fewer variables than the EFFECTS data file. The EFFECTI data file is sorted prior to the initiation of the SAS procedure for creating the disk file '\&\&T' using the cormand "PROC PRINTTO UNIT=4NEW;". The number 4 in this command corresponds to a 4 in the IBM Job Control Language "//SAS.FTØ4Føळ1" in the beginning of Table 3.2-1. The code which is included between the "PROC PRINTTO" commands is used to output the data files which have been created and arranged with the previous code. Even though the commands imply printing, the data will be output to the "FTø4Føø1" data file. Imbedded within these output statements is the sixth and final data file to be included in the disk file. The statements begin with "DATA NULL_;" and end with "PUT INFILE;". These five statements are used to output a file which has been created on the DECSYSTEM10 and contains citations for the "References" portion of the disk data file. 
The final 12 IBM JCL statements execute a program, LCOM, which uses the previously created disk file as input and creates a magnetic tape file with the desired format for microfiche generation.

The listing presented in Table 3.2-1 has been used to generate a microfiche as a pocket insert to a Division publication (Cushman, R. M., S. G. Hildebrand, R. H. Strand, R. M. Anderson. 1977. Toxicity to Freshwater Biota of 35 Trace Elements in Coal: A Data Base with Automated Retrieval Capabilities. ORNL/TM-4792). The reader is referred to this document for the actual microfiche discussed above. While we realize this is a very lengthy example, it illustrates very nicely the way an entire document could be placed on microfiche or just the appendix material, if desired. The simplicity of only two SAS statements, a JCL statement describing the disk file for saving the uutpul for a second program, and the CSD's computer program "LCOM" for generating the magnetic tape is quite encouraging to those who desire to use microfiche in the ir SAS programing. It should be noted that the magnetic tape must then be transferred to $K-25$ along with a microfiche request form (UCN-7342) properly instructing the operator at K-25 on the number of copies desired, tape number, and other information requested on this form.

For authors desiring to include microfiche in their publications, there are requirements set by National Technical Information Service for publishing a paper or report with microfiche. These requirements would cause the microfiche generated by the program LCOM in our example to be unacceptable. For details on these requirements, see the Division editor. The senior author of this guide has a computer program available which will generate a microfiche acceptable to NTIS.

\subsubsection{Card image output as a punched file from IBM 360 Computers to MODCOMP RBS}

If a user wants punched output from an IBM 360 computer job saved as a card image file rather than a physical card deck, it is possible to have this data saved as a magnetic tape card image file on the MODCOMP. This would allow a user to submit this "punched" output repeatedly into successive jobs. To perform this, the user must inform the MODCOMP RBS operator of the job name and place the following card in $h$ is program deck:

\section{$/ *$ ROUTE PUNCH REMOTE1Ø}

\subsubsection{Data processing examples using SAS}

With this note we intend to introduce the interested user to the capabilities of the Statistical Analysis System (SAS), (illustrating the batch and interactive commands and showing some of the ways SAS handles data.) 


\subsubsection{Batch SAS}

Table 3.2-1 in section 3.2.6 gives a listing of a batch version of a SAS program to input data files and print them in tabular form with variables being modified, created, and/or deleted. The interested user will find that the SAS User's Manual contains explicit examples of SAS output in batch mode. We suggest users consult this manual for suggestions on how to use SAS in the batch mode.

The user is able, with SAS, to perform various statistical calculations on the data sets created with INPUT, SET, MERGE or OUTPUT statements as described in the SAS User's Guide (See Table 1.1-1 for contact person to obtain this computer manual).

\subsubsection{Interactive SAS}

SAS (version 76.4) has been implemented on the IBM 360 model 75 as an interactive program. This allows data sets which are stored on disk to be analyzed and displayed interactively. The user may also analyze data by entering it directly at the terminal.

Users who wish to take advantage of the facilities for interactive SAS programming should read the section on Time Sharing Option (TSO) operation of SAS in the SAS76 User's Guide (pages 296-299). The SAS system also has an editor for use with SAS interactive. This editor allows for editing of files as lines created in a TSO/SAS session. All the details of the TSO/SAS version are not explained in this note. Instead, the commands necessary to set up a TSO/SAS session, the procedures for invoking these commands, and a sample run showing the examples of a TSO/SAS session are presented.

The comands necessary for setting up a TSO/SAS session are given in Table 3.2-2. These commands should be entered exactly as shown into a file in the user's area. This file is called SAS76.CLIST for this examp le.

After logging onto TSO, the procedure for executing this file is to type "EXEC SAS76" (Table 3.2-3). Messages are returned to the user as the commands are executed. The successful setup of a TSO/SAS session will be indicated to the user by a "1?" typed on the terminal. In our example we name a data set "FISH" and after defining the variables, enter the data at the terminal. The "RUN;" command tells SAS to execute what has been entered up to the last "RUN;" statement or from the beginning of the session, whichever is first. The user may then specify a procedure or a number of procedures for execution. When the user desires that these procedures be executed, the "RUN;" statement followed by a carriage return is entered. (Each line is terminated with a carriage return in the example). 
Table 3.2-2. Commands for establishing an interactive TSO/SAS session using SAS 76.4

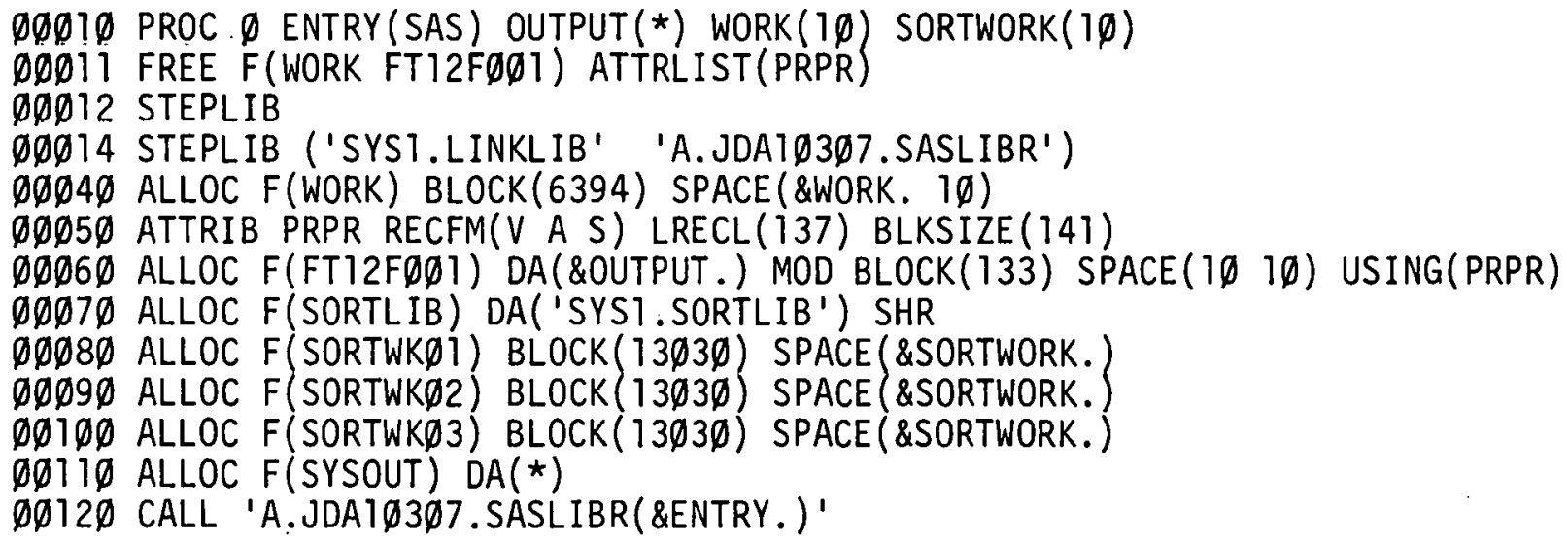


Table 3.2-3. A sample execution of TSO/SAS interactive (underscored materials are user entered; each line of entered material is terminated with a carriage return)

\author{
EXEC SAS76 \\ IKJ56234I ATTR-LIST-NAME PRPR NOT FOUND \\ IKJ56247I UTILITY DATA SET NOT FREED, IS NOT ALLOCATED \\ IKJ56247I UTILITY DATA SET NOT FREED, IS NOT ALLOCATED \\ IKJ56103I MOD, BLOCK,SPACE OPERAND IGNORED FOR TERMINAL DATA SET \\ 1 ?DATA FISH; INFILE CARDS; INPUT X Y1 Y2 Y3 Y4 GROUP; \\ 2?CARDS: \\ $3 ? 10 \quad 35 \quad 45 \quad 56 \quad 76 \quad 1$ \\ $4 ? \longdiv { 2 3 7 4 4 5 8 6 8 1 }$ \\ $5 ? 13 \begin{array}{llllll}44 & 39 & 5977 & 77\end{array}$ \\ $6 ? 1134 \quad 475579 \quad 1$ \\ $7 ? \longdiv { 1 0 3 9 5 4 \quad 6 2 \quad 8 5 2 }$ \\ $8 ? 1 \longdiv { 2 3 9 4 7 6 1 8 5 2 }$ \\ $9 ? 13494263892$ \\ $10 ? 11 \quad 36 \quad 51 \quad 58 \quad 832$ \\ 11 ?RUN: \\ NOTE: DATA SET WORK.FISH HAS 8 OBSERVATIONS AND 6 VARIABLES. \\ 12?PROC GLM; MODEL Y $1=X ;$ RUN:
}


Table 3.2-3. (continued)

GENERAL LINEAR MODELS PROCEDURE

DEPENDENT VARIABLE INFORMATION

NUMBER OF OBSERVATIONS IN DATA SET $=8$

GENERAL LINEAR MODELS PROCEDURE

DE PENDENT VARIABLE: Y1

SOURCE

$D F^{\prime}$

SUM OF SQUARES

MEAN SQUARE

MODEL

1

99.22500000

99.22500000

ERROR

6

79.65000000

13.27500000

CORRECTED TOTAL

178.87500000

MODEL $\mathrm{F}=$

$\mathrm{PR}>\mathrm{F}=0.0340$

R-SQUARE

C.v.

STD DEV

Y1 MEAN

0.554717

9.3124

3.64348734

39.12500000

SUURCE

DE'

TYPE I SS

F VAlUe

$\mathrm{P} \Omega>\mathrm{F}$

$\mathrm{X}$

1

99.22500000

7.47

0.0340

SOURCE

$\therefore \quad$ DF

TYPE IV 33

F VALUE

$\mathrm{PR}>\mathrm{F}$

$\mathrm{x}$

1

99.22500000

7.47

0.0340

$\begin{array}{lrrrr}\text { PARAMETER } & \text { ESTIMATE } & \begin{array}{c}\text { T FOR H0: } \\ \text { PARAMETER }=0\end{array} & \text { PR }>|T| & \begin{array}{c}\text { STD ERROR OF } \\ \text { ESTIMATE }\end{array} \\ \text { INTERCEPT } & 2.90000000 & 0.22 & 0.8348 & 13.31244718 \\ \mathrm{X} & 3.15000000 & 2.73 & 0.0340 & 1.15217186 .\end{array}$

13?PROC MEANS DATA=FISH; VAR X Y1 Y2 Y3 Y4; RUN; 
Table 3.2-3. (continued)

\begin{tabular}{|c|c|c|c|c|c|}
\hline VARIABLE & $\mathbf{N}$ & MEAN & $\begin{array}{l}\text { STANDARD } \\
\text { DEVIATION }\end{array}$ & $\begin{array}{l}\text { MINIMUM } \\
\text { VALUE }\end{array}$ & $\begin{array}{l}\text { MAXIMUM } \\
\text { VALUE }\end{array}$ \\
\hline X & 8 & 11.50000000 & 1. 19522861 & 10.00000000 & 13.00000000 \\
\hline Y1 & 8 & 39.12500000 & 5.05505405 & 34.00000000 & 49.000000000 \\
\hline Y2 & 8 & 46.12500000 & 4.79396943 & 39.00000000 & 54.000000000 \\
\hline Y3 & 8 & 59.00000000 & 2.82842712 & 55.00000000 & 63.000000000 \\
\hline Y4 & 8 & 80.25000000 & 6.64938236 & 68.00000000 & 89.00000000 \\
\hline
\end{tabular}

14?OPTIONS PS $=34$ TLS $=72$;

15 ?PROC SCATTER; PLOT X*Y1; RUN;

PLOT OF X*Y1 LEGEND: $A=1$ OBS, $B=2$ OBS, ETC

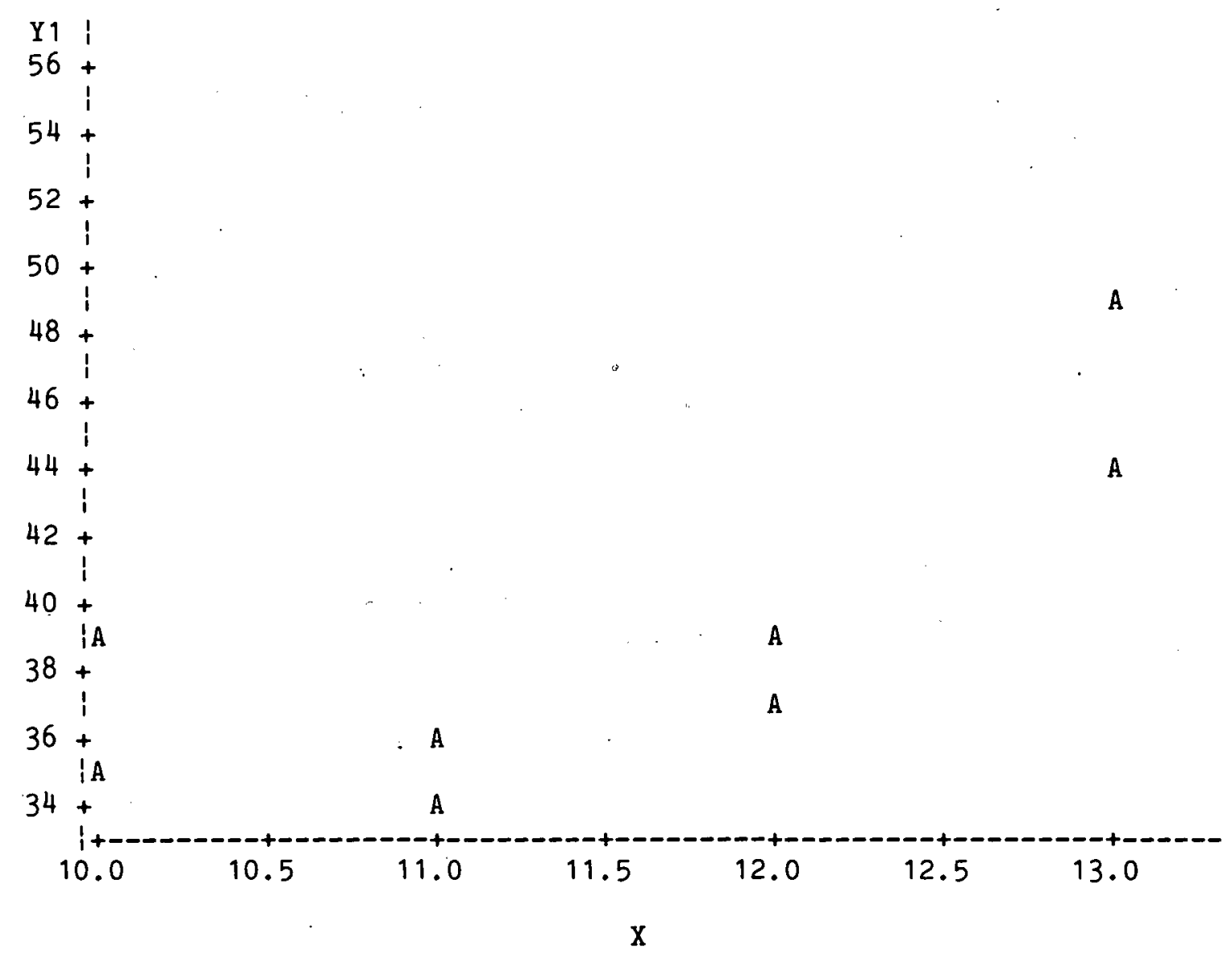

$16 ? /$ *

NOTE: SAS INSTITUTE INC., P.O. BOX 10066, RALEIGH, N.C. 27605 
For the hypothetical data set "FISH", the SAS procedures GLM, MEANS, and SCATTER are executed. The output from these procedures is indicated after each procedure cal1. Note that the procedure for setting the height (PS=34) and width (TLS=72) of the page for PROC SCATTER is necessary to include the plotted output on a single page of an 80-column wide terminal.

The statements and data which have been entered in this terminal session can be entered by using the TSO/SAS editor. This procedure is invoked by typing "PROC EDITOR; RUN;" The user is instructed by SAS from that point forward as to what commands to enter.

Some users may find it useful to know that they can access their online IBM 360 disk data sets (at Bldg. 4500N) by allocating these data sets prior to executing SAS76.CLIST. The command for allocating a data set is as follows:

ALLOC $F$ (name) DA('data set name') SHRt

A "name" is 1-8 characters; the 'data set name' corresponds to the job control language data set name under which it is stored on a disk in the computer. To use this data set in a TSO/SAS session, the following can be specified:

1 ?DATA A; INFILE name; INPUT ...;

2? RUN; +

Here the data set is a card image data set which requires definition or the variables, their type, and card column location in the SAS INPUT statement. If the data set is stored as a SAS data set, the user can specify the data set as follows:

1? DATA A; SET name. leve 1; RUN; $\downarrow$

In this example the "name" is the valid name as specified in the "F(name)" of the ALLOC command above, while the "level". is the level specified for the data set when it was created by the SAS user.

Several other ways of allocating data sets and accessing files are possible. Not all of them are shown here, but if a user can master the material presented here, the available manuals can be read, and the other ways of data access and data set processing can be determined. 
3.2.9 Procedure for creating data sets on the DECSYSTEM10 from IBM's Cont inuous System Modeling Program (CSMP)

A procedure for creating data sets on the DECSYSTEM10 containing variables for statistical routines or graphical display from CSMP* is described. A single data set or multiple data sets can be created with a single CSMP run. Data set reference numbers 01, 02, 03, 05, 06, 07 , $08,13,14$, and 15 may not be used for defining user data sets. These data set reference numbers are used in CSMP for various data sets created by CSMP during the simulation.

An example of the IBM JCL followed by an explanation of the coded instructions (enclosed in parentheses) follows:

//JAW2Ø JOB (15429), 'SAVE 6290,64 WATTS' (Defines DECSYSTEM10 disk area)

$/ / *$ CLASS CPU9 $1=3 \emptyset S, C A R D S=50$ (CARDS option needed if more than 1000 cards punched)

//*ROUTE PRINT REMOTE10 (Routes print to RBS in 2001)

//*ROUTE PUNCH REMOTE5 (Needed if job submitted via cards rather

// EXEC CSMPIII

user-supplied CSMP routines

//FT20FDD1 DD SYSOUT $=(K,, 9900)$ (Routes output defined by data set reference number 20 to DECSYSTEM10 as a punch file)

//FT21F001 DD SYSOUT $=(K,, 9950)$ (Routes output defined by data set reference number 21 to DECSYSTEM10 as a punch file)

$/ *$

Note: The last two digits of SYSOUT field, i.e., 99xx can be any two digits, as long as each is unique for a data set being created.

In the INITIAL section of the CSMP deck, the filenames corresponding

to the data set reference number in the IBM JCL are defined.

EXAMPLE:

INITIAL

NOSORT

10 FORMAT ('NAMEBETA3.DAT')

WRITE $(21,11)$

11 FORMAT ('NAMEBETA4.DAT')

SORT

*IBM. Continuous System Modeling Program III. Programmers Reference Manual. SH19-7001-2. 
The criterion for variables to be defined in the appropriate data set is given in the DYNAMIC section of CSMP.

EXAMPLE:

NOSORT

BETMOD $=A M O D$ (YEAR, OUTDEL)

IF (BETMOD .NE. Q.99) GO TO 43

IF (BETA $\emptyset$.EQ. $\emptyset .3$.AND. KEEP .EQ.1) WRITE $(2 \varnothing, 2 \varnothing)$ YEAR, C1, $1 \mathrm{C} 3, \mathrm{C} 4, \mathrm{C} 7, \mathrm{C} 8$

20 FORMAT (F5. $\varnothing, 5 E 12.3)$

IF (BETAø.EQ. $\emptyset .4$. AND. KEEP. EQ.1) WRITE $(21,2 \varnothing)$ YEAR, C1 $1 \mathrm{C} 11, \mathrm{C} 12, \mathrm{C} 13, \mathrm{C} 14$

SIRT

CONTINUL

The KEEP variable is tested at each integration step, with KEEP=1 at the end of the integration step. Thus results are written into the file only at the end of each integration after all the intermediate trial and prediction calculations have been completed and the error criteria satisfied.

If results had been desired only at the completion of a similation run, i.e., FINISH TIME, then FORTRAN statements reflecting this could be placed in the TERMINAL section of the CSMP deck as in the DYNAMIC section.

The DECSYSTEM10 data set output is in addition to that obtained in the OUTPUT or PRINT mode of CSMP, printed on the line printer. III II way is the normal output altered.

There are a number of CSMP variables availahle to the user for testing and user control. The Continuous System Modeling Program III (CSMP III) Program Reference Manual (SH19-7001-2) should be consulted for further information. (See Table 1.1-1 for contact persons within the Environmental Sciences Division.)

An interactive version of CSMP is available on the DECCSYSTEM10. For information on this program, type "HELP CSMP $\downarrow$ " after logging into the DECSYSTEM10.

\subsubsection{Computer Graphics using DISSPLA}

\subsubsection{Batch--DISSPLA on the DECSYSTEM10}

The DISSPLA Computer graphics package is available at the main computer, $X-10$ and $K-25$ sites. The available manuals can be obtained from CSD computer librarian, 3-1703, or see the ESD computer manuals contact person listed in Table 1.1-1. The structuring of a computer 
program example for this guide, that would be generally useable, was considered impractical and would depart from the intent of the guide. We recommend ESD programming assistance (See Table 1.1-1) for users interested in further plotting assistance and examples. The JCL is the same at both sites but the user does need to determine that the device requested is available at that particular site.

To use DISSPLA in a FORTRAN program that is being submitted as a batch job to the IBM 360 s and generate a CALCOMP-type copy of the plot, a table is presented to give the user logical sequence of control cards and program cards (Table 3.2-4). The exact description of each card is not presented in this table but is referred to in the discussion which follows.

DISSPLA was written to be as machine independent as possible. When DISSPLA is used, you must have in your FORTRAN program a call to a device initialization routine prior to any plotting subroutine calls. These device declarations and the necessary IBM Job Control Language for each are as follows:

CALL CALCMP

This CALL initializes DISSPLA for the CALCOMP drum plotter using a plot tape. IBM JCL is given in Chapter 13 of the Programmers Notebook. We will reproduce some of the JCL here to illustrate our examples. IBM JCL for the Linkage Editor (LKED) step would be

//LKED.SYSLIB DD

$/ / \mathrm{DD}$

$/ / \mathrm{DD}$

// DD DSN=DISSPLA.LOAD, DISP=SHR

and JCL for the GO step

//GO.PLOTTAPE DD UNIT $=$ TAPE7, VOL $=S E R=\varnothing 1$, LABEL $=(, N L), D I S P=0 L D$

Disk plots are also available. Initialize the device for a disk plot with a call to CALCMP and the following IBM JCL for the LKED step:

//LKED.SYSLIB DD

$/ / \mathrm{DD}$

$/ / \mathrm{DD}$

// DD DSN=DISSPLA. LOAD, DISP=SHR

//LKED.PLOTSUBS DD DSN=JGSPLOTH, DISP $=S H R$

//LKED.SYSIN DD *

/*

INCLUDE PLOTSUBS 
Table 3.2-4. Logical sequence of program and control statements for executing a batch FORTRAN program with DISSPLA plotting

\begin{tabular}{|c|c|c|}
\hline ITEM NO. & DESCF & PTION \\
\hline 1 & NU SEUUENCE CARD & $\begin{array}{r}\text { (OPTIONAL-FOR TAFES, DISKS OR } \\
\text { SPECLIAL INS'IKULIIUUNS) }\end{array}$ \\
\hline 2 & JOB CARD & (REQUIRED-UNIQUE TO EACH USER) \\
\hline 3 & CLASS CARD & (REQUIRED-GIVES REQUIREMENTS OF JOB) \\
\hline 4 & PLOT CARD & (OPTIONAL-FOR TAPE OR SPECIAL PLOTS) \\
\hline 5 & ROUTE CARD & (OPTIONAL-FOR ROUTING PRINT OR PUNCH OUTPUT) \\
\hline 6 & $\begin{array}{l}\text { EXECUTE FORTRAN } \\
\text { COMPILE, LINK, \&GO }\end{array}$ & (REQUIRED) \\
\hline 7 & SYSIN DD $*$ CARD & (REQUIHED-YHELELEES FORTRAN DECK) \\
\hline 8 & $\begin{array}{l}\text { FORTRAN PROGRAM } \\
\text { \& WSSPIAA GARTSS }\end{array}$ & (REQUIRED) \\
\hline 9 & $\begin{array}{l}\text { LINKAGE EDITOR } \\
\text { COMMAND CARDS }\end{array}$ & (REQUIRED-DIFFERENT FOR DISK TH NN TAPE) \\
\hline 10 & $\begin{array}{l}\text { GO STEP OUTPUT } \\
\text { CARDS }\end{array}$ & (RFQUTIRED-DIFFERENT FOR DISK THAN TAPE) \\
\hline
\end{tabular}


JCL for the GO step would be

//GO.FT49Føの1 DD UNIT =IN20U2, DISP = (NEW,KEEP),

// SPACE $=(32 \emptyset 8,4 \emptyset, \mathrm{RLSE}), \mathrm{DSN}=\mathrm{PLOT} \emptyset 0$. name,

$/ / \mathrm{DCB}=(\mathrm{RECFM}=\mathrm{VS}, \mathrm{LRECL}=32 \emptyset 4, \mathrm{BLKS}$ IZE $=32 \emptyset 8)$

\section{CALL FILM ('name\$')}

This initializes DISSPLA for the CALCOMP Cathode Ray Tube (CRT) plotter. The character string 'name $\$$ ' is used as plot identification and is passed to the CRT programs. IBM JCL for the LKED step would be the same as in part 1 of this section and JCL for the GO step would be

$/ /$ GO.CRT TAPE DD UNIT $=$ TAPE9, VOL $=S E R=n n$,

// LABEL $=(, N L), D I S P=0 L D$

CALL PRTPL

This initializes DISSPLA to output graphs to the line printer. This type of plot should be used for debugging purposes. JCL for the LKED step would be the same as in part 1 of this section. Output in the GO step is on the standard FORTRAN output file FTO6F001 and will be supplied by the cataloged procedure FORTHCLG or FORTGCLG (See Chapters 8 and 16, Programers Notebook).

\section{CALL EAI}

This initializes DISSPLA to use the flatbed plotter with $11 \times 17$ inch paper. It is mandatory that the library DISSPLA.LOAD preceed the normal EAI library SYS1.EAILIB. IBM JCL for the LKED step would be the same as in part 1 of this section, and JCL for the GO step would be

//GO.FT15FDD1 DD DSN=PLOTTAPEX, UNIT=TAPE7, $/ /$ DISP $=($ NEW, KEEP $)$

\section{CALL EAI3D}

This initializes the flatbed plotter with $30 \times 30$ inch paper. Again the library DISSPLA.LOAD must preceed the EAI library SYS1.EAILIB. The JCL is identical to that used in the CALL EAI.

CALL TEKTRN(ICPS)

This initializes DISSPLA to produce graphs on a TEKTRONIX terminal screen where ICPS is the line speed; i.e., ICPS $=3 \emptyset$ for $3 \emptyset \emptyset$ BAUD ( $3 \emptyset$ cps). The batch mode LKED JCL would be 
//LKED.SYSLIB DD

$/ / \mathrm{DD}$

$/ / \mathrm{DD}$

// DD DSN=DISSPLA.LOAD,DISP=SHR

// DD DSN=TEK. TEKLOAD. LOAD, DISP=SHR

where TEK. TEKLOAD.LOAD is the TEKTRONIX Terminal Control System (TCS). IBM's Time Sharing Option (TSO) on line link edit would include

LIB('DISPPLA.LOAD' 'TEK.TEKLOAD.LOAD')

to allocate the DISSPLA and the TEKTRONIX TCS.

CALL CUMPRS

This initializes DISSPLA to generate the device independent compressed DISSPLA data set. JCL for the LKED step would be

//LKED.SYSLIB DD

$/ / \mathrm{DD}$

$/ / \mathrm{DD}$

// DD DSN=DISSPLA. LOAD,DISP=SHR

JCL for the GO step must allocate to the DDNAME COMPOUT, the dataset to receive compressed data. The compressed data set can reside on any device supporting fixed records of length $4 \sigma \phi \emptyset$. SPDA datasets would be a good choice for these datasets. JCL for the GO step might be

$/ /$ GO. COMPOUT DD DSN=T.ÄBCø2345. name, UISP=(NEW, CATLG),

// UNIT $=$ SPDA, SPACE $=($ TRK,$(5,5)$, RLSE $)$

(See ESD Programming Assistance, Table 1.1-1, for assistance on DSN naming conventions on SPDA.) The postprocessor of DISSPLA reads the data set generated by a COMPRS call. This allows the user to manipulate the plots generated and stored by DISSPLA on a disk file. More details on using the postprocessor commands are available in documentation distributed by CSD (call J. Carpenter, 3-1703, for copy). The CLIST required for executing the postprocessor is given below:

FREE FILE(FTø5Føø1)

FREE FILE(FTø6FØØ1)

FREE FILE (COMPIN)

ALLOC F(FT95FO91) DA(*)

ALLOC F(COMPIN) DA( DATA.) OLD

FREE ATTRLIST (CRT)

ALLOC F(FTø6FØø1) DA(*) USING(CRT)

CALL DISSPLA.DISSPOP.LOAD (TEKPOP) 
Replace DATA. by the appropriate dataset name (DSN=) used in "GO.COMPOUT" data set.

It should be noted that with the CALL CALCMP for tape plots and CALL FILM for CRT plots, your deck should contain the following three cards in order to generate a plotter work request card. (See CSD Programer's Notebook for details on these cards.)

(1) a //^NOSEQCARD must be present before the JOB card

(2) the $/ / *^{*}$ CLASS card must have SPECIAL=TAPE option

(3) a // $A P L O T$ card must be present within the front portion of the. $\mathrm{JCL}$.

\subsubsection{Interactive--DISSPLA on the DECSYSTEM10}

The plotting of data using DISSPLA in an interactive mode differs from the batch mode previously described--no control cards precede or follow the FORTRAN program. A user needs only to be logged into the DECSYSTEM10 and have or create a FORTRAN program with a file name.

In order to have a program plot directly on a TEKTRONIX (4012, or 4014) terminal screen, the first plotting call in your FORTRAN program must be

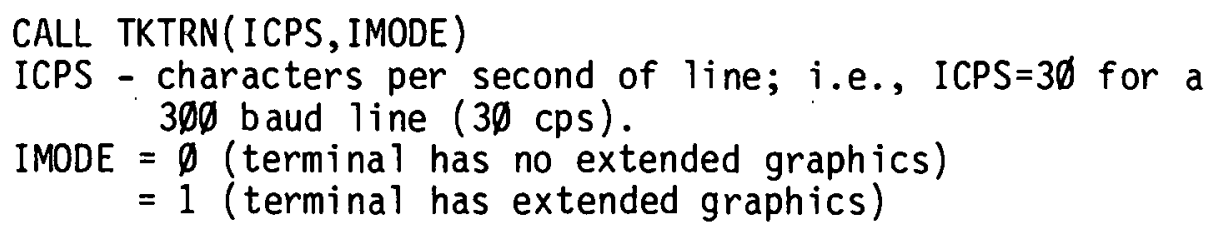

To execute the program:

.ASSIGN TTY LPT $\downarrow$

.EX yourpgm,QSYS:DISTEK $\downarrow$

These plots may be submitted to the IBM 360 for plotting on other devices. See CSD documentation on using DISSPLA's postprocessor.

Also plot data created on the IBM 360 machines at B1dg. $4500 \mathrm{~N}$ may be sent to the DECSYSTEM10 for viewing on a TEKTRONIX terminal screen by generating a device-independent compressed data (CALL COMPRS) set and sending this dataset in its compressed form to the DECSYSTEM10. (See Chapter 13 Programer's Notebook for sending plot data to the DECSYSTEM10). 


\section{DATA PROCESSING SOFTWARE}

Several computer programs are available to users for data processing. These programs fall into three general categories: (1) complete systems which have the ir own syntax and language as an independent data processing system, (2) subroutine packages which are aggregates of subroutines to which the user must supply a main program, and (3) special purpose programs designed for a specific data processing function and implemented with a single user in mind. All of these approaches have their conveniences and inconveniences. The systems are powerful, widely applicable, and production-oriented, but require the user to learn a programming syntax and command structure. The subroutine packages are convenient pieces which can be attached to a user's main program, but require the user to program a main routine and interface the main and subroutine portions of the program. Special.purpose programs are severely restricted in the1r applications and difficult to modify for another purpose. The user who is interested in determining the software avallable fur $h$ is particular needs is referred to ESD programing assistance (Table 1.1-1). 
ORNL/TM-5966

INTERNAL DISTRIBUTION

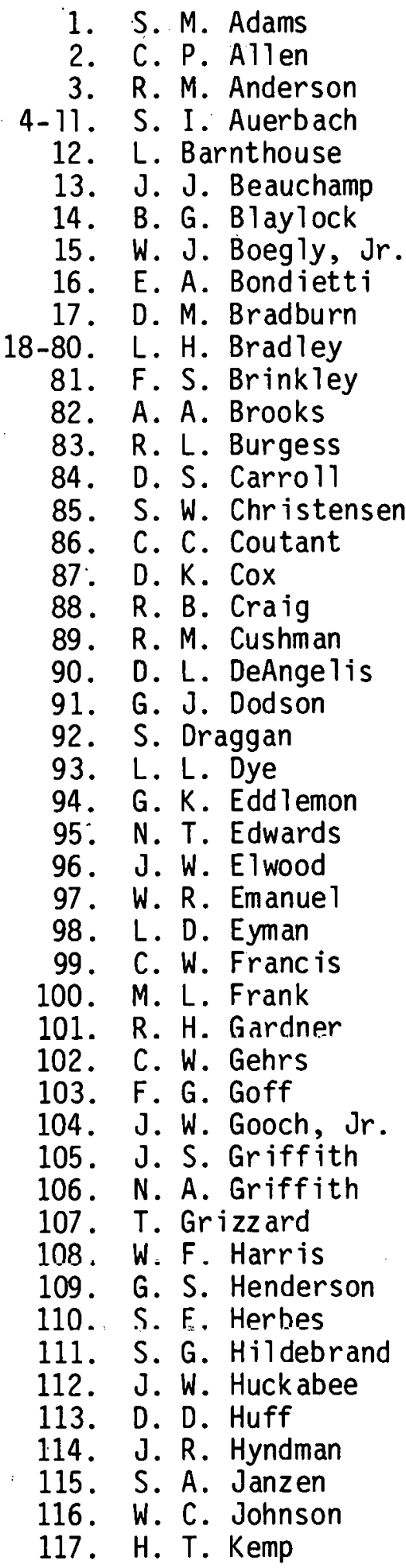

118. R. L. Kroodsma

119. D. Kumar

120. S. E. Lindberg

121. R. J. Luxmoore

122: J. B. Mank in

123. L. K. Mann

124. D. Matt

125. J. S. Mattice

126. R. K. McConathy

127. S. B. McLaughlin

128. R. B. McLean

129. J. D. Newbold

130. J. S. Olson

131. R. J. 01 son

132. R. V. O'Neill

133. B. R. Parkhurst

134. P. D. Parr

135. D. C. Parzyck

136. G. B. Raine

137. D. E. Reichle

138. i. R. Richmond

139. M. Ross

140. R. K. Schreiber

141. M. H. Shanks

142. D. S. Shriner

143. H. H. Shugart

144. G. R. Southworth

145. J. D. Story

146-167. R. H. Strand

168. E. G. Struxness

169. J. S. Suffern

170. F. H. Sweeton

171. F. G. Taylor, Jr.

172. M. L. Tharp

173. D. E. Todd, Jr.

174. R. R. Turner

175. R. I. Van Hook, Jr.

176. P. Van Vor is

177. W. Van Winkle, Jr.

178. J. A. Watts

179. D. C. West

180-181. Biology Library

182-183. Central Researh Library

184-185. Laboratory Records Dept.

186-187. Laboratory Records, ORNL-RC

188. ORNL Y-12 Technical Library

189. ORNL Patent Office 


\section{EXTERNAL DISTRIBUTION}

190. J. Wilson, ERDA Headquarters, Washington, DC 20545

191. Jeff Swinebroad, Division of Biomedical and Environmental Research, ERDA, Washington, DC 20545

192. Bill Osburn, Energy Research and Development Administration, Washington, DC 20545.

193. Research and Technical Support Division, ERDA-ORO

194-220. Technical Information Center 